\title{
Physiological and transcriptional analyses of developmental stages along sugarcane leaf
}

Lucia Mattiello ${ }^{1,5^{*}}$, Diego Mauricio Riaño-Pachón ${ }^{1}$, Marina Camara Mattos Martins ${ }^{1}$, Larissa Prado da Cruz ${ }^{1}$, Denis Bassi ${ }^{1}$, Paulo Eduardo Ribeiro Marchiori ${ }^{2}$, Rafael Vasconcelos Ribeiro ${ }^{3}$, Mônica T. Veneziano Labate ${ }^{4}$, Carlos Alberto Labate ${ }^{4}$ and Marcelo Menossi ${ }^{5}$

\begin{abstract}
Background: Sugarcane is one of the major crops worldwide. It is cultivated in over 100 countries on 22 million ha. The complex genetic architecture and the lack of a complete genomic sequence in sugarcane hamper the adoption of molecular approaches to study its physiology and to develop new varieties. Investments on the development of new sugarcane varieties have been made to maximize sucrose yield, a trait dependent on photosynthetic capacity. However, detailed studies on sugarcane leaves are scarce. In this work, we report the first molecular and physiological characterization of events taking place along a leaf developmental gradient in sugarcane.

Results: Photosynthetic response to $\mathrm{CO}_{2}$ indicated divergence in photosynthetic capacity based on PEPcase activity, corroborated by activity quantification (both in vivo and in vitro) and distinct levels of carbon discrimination on different segments along leaf length. Additionally, leaf segments had contrasting amount of chlorophyll, nitrogen and sugars. RNA-Seq data indicated a plethora of biochemical pathways differentially expressed along the leaf. Some transcription factors families were enriched on each segment and their putative functions corroborate with the distinct developmental stages. Several genes with higher expression in the middle segment, the one with the highest photosynthetic rates, were identified and their role in sugarcane productivity is discussed. Interestingly, sugarcane leaf segments had a different transcriptional behavior compared to previously published data from maize.

Conclusion: This is the first report of leaf developmental analysis in sugarcane. Our data on sugarcane is another source of information for further studies aiming to understand and/or improve $\mathrm{C}_{4}$ photosynthesis. The segments used in this work were distinct in their physiological status allowing deeper molecular analysis. Although limited in some aspects, the comparison to maize indicates that all data acquired on one $C_{4}$ species cannot always be easily extrapolated to other species. However, our data indicates that some transcriptional factors were segment-specific and the sugarcane leaf undergoes through the process of suberizarion, photosynthesis establishment and senescence.
\end{abstract}

Keywords: Sugarcane, Photosynthesis, RNA-seq

\footnotetext{
* Correspondence: lucia@lgf.ib.unicamp.br

'Laboratório Nacional de Ciência e Tecnologia do Bioetanol (CTBE), Centro

Nacional de Pesquisa em Energia e Materiais (CNPEM), Caixa Postal 6192,

13083-970 Campinas, SP, Brazil

${ }^{5}$ Laboratório de Genoma Funcional, Instituto de Biologia, Universidade

Estadual de Campinas Campinas, Caixa Postal 6109, Campinas 13083-862SP,

Brazil

Full list of author information is available at the end of the article
} 


\section{Background}

Sugarcane is a tropical crop with $\mathrm{C}_{4}$ photosynthetic metabolism and Brazil is its main producer. World's interest in bioethanol and sugarcane with high sucrose and biomass yield has increased continuously over the years. In fact, sugarcane is one of the most important crops used as sustainable feedstock for renewable energy, such as bio-electricity and bioethanol, in tropical and subtropical regions (International Energy Agency - http://www. iea.org). Worldwide, sugarcane is cultivated in 22 million ha and its average yield is 70.9 Tonnes/ha [1]. This crop is very efficient in intercepting solar energy and assimilating carbon into carbohydrates, which results in high sucrose accumulation (around $0.7 \mathrm{M}$ ) in its mature culms and high biomass production [2]. However, the current average yield is less than $20 \%$ of the theoretical maximum estimated from mathematical models of plant growth and physiological processes [3]. Photosynthesis plays a key role on biomass production and crop yield, however, our understanding about this important physiological process in sugarcane is more limited when compared to maize, another $\mathrm{C}_{4}$ species. This highlights the need for detailed sugarcane physiology studies, particularly on leaf photosynthesis. Such efforts would aid bridging the gap between the average yield in the field and the theoretical maximum yield of sugarcane.

Modern sugarcane originated from inter-specific hybridization between the parental species Saccharum officinarum L. $(2 \mathrm{n}=80)$ and S. spontaneum L. $(2 \mathrm{n}=40-128)$. Despite its economic importance, the complexity of the sugarcane genome [4-6] with its haploid genome size estimated of $930 \mathrm{Mbp}$ and high ploidy, aneuploidy and polymorphism, $[4,7,8]$ have limited the advances on the development of new varieties via molecular breeding approaches. Classical breeding has been the only responsible for sugarcane varieties released in the last decades [1], although some efforts exploiting genetic modification have been carried out [9-13]. It is worth noting that, to the best of our knowledge, no transgenic line has been commercially released yet $[14,15]$.

Sugarcane was brought to Brazil in 1531 and despite the enormous agronomic work to generate more productive lines, the understanding of the sugarcane physiology, especially in relation to its photosynthetic performance, is still lacking [16]. Modern cultivars have been selected mainly for characteristics based on nutritional demand and resistance to biotic and abiotic stresses, and not for photosynthetic activity, as has being done for the wheat and rice breeding programs [17]. Recent studies indicate a positive correlation among photosynthesis, crop yield and biomass production, suggesting that increasing photosynthesis is a potential way to enhance sugarcane productivity [16, 18-20].
In order to increase and/or manipulate sugarcane photosynthesis we must first understand the regulatory processes involved in $\mathrm{C}_{4}$ biochemistry [21]. $\mathrm{C}_{4}$-type photosynthetic metabolism is more efficient than the $\mathrm{C}_{3}$-type due to some physiological, biochemical and anatomical specific features $[18,22]$. Species with $\mathrm{C}_{4}$ metabolism appeared independently at least 45 times during land plant evolution [23] in a minimum of 62 monocot and dicot plant species around 30 and 15 million years ago, suggesting that relatively simple genetic and regulatory mechanisms can drive the conversion of a $C_{3}$ phenotype into $C_{4}[24]$. Nevertheless, the mechanisms and regulatory players are not yet fully understood.

Besides environmental factors, photosynthesis is also controlled by the sink strength balancing source supply and sink demand [25-29]. In this context, the activity of enzymes and the expression of genes related to photosynthesis follow the source-sink relationship in sugarcane [26, 30-35]. Consequently, many studies evaluating gene expression have focused mainly on the sink, i.e., sugarcane culm development, providing insights into culm maturation and sucrose accumulation [36-40]. In contrast, only few studies have explored the physiological and biochemical causes of photosynthesis variation among cultivars and leaf types [16, 20, 41, 42].

Leaves of grasses are excellent systems to study the establishment of $\mathrm{C}_{4}$ photosynthesis because there is a cellular developmental gradient along the leaf blade, with the basal cells being undifferentiated and immature and the cells towards the tip becoming more mature and specialized [43-49]. The most studied $C_{4}$ species is maize, with several works describing transcriptomic, proteomic and metabolomic differentiation along the leaf blade [43-48]. Leaf development has been studied in rice and compared to maize leaves in order to identify key regulatory components and metabolite profiles for $\mathrm{C}_{4}$ phenotype [48]. So far, there is no similar report on $\mathrm{C}_{4}$ species other than maize.

The molecular mechanisms for $\mathrm{C}_{4}$ leaf development are complex and this process in polyploid and aneuploid plants such as sugarcane remain largely unknown. In order to fill this gap, we have carried out a detailed study of sugarcane leaf to investigate molecular and physiological changes along the leaf blade segments representing different developmental stages. The approaches used in this work allowed us to identify differences in compounds and enzymes responsible for the variable photosynthetic capacity among leaf segments, and several relevant genes that might be subjected to further studies in order to increase photosynthesis and productivity.

\section{Results and discussion Leaf sampling}

Despite being clonally propagated, sugarcane has a heterogeneous germination rate and initial vegetative 
growth. In order to standardize our experiment, we conducted a pilot study to evaluate the plant age at which the highest number of leaves would have the same length and also guarantee that all stalk reserves have been consumed in a way that the plants were solely dependent on photosynthesis for growth. The length distribution of leaf +1 (the first with the dewlap fully exposed) of 60 day-old plants is depicted on Figure S1 (Additional file 1). Leaves with length between 52.3 and $57 \mathrm{~cm}$ had the highest frequency $(20 \%)$ and this group was considered nearly homogenous and harvested for further analysis. The plant phenotype is shown in Figure S2 (Additional file 1). Additionally, to overcome the length difference, even in the homogeneous population, we collected leaf segments taking into account the proportion of each segment on each length and not a fixed distance from the base of the leaf. The segments were named Base "zero" (B0); Base (B); Middle (M) and Tip (T) (see Materials and Methods and Figure S3 Additional file 1).

\section{Physiological and biochemical evaluations}

In order to characterize sugarcane leaf segments, several physiological and biochemical evaluations were performed. We used intact leaves and were able to evaluate gas exchange and photochemistry only on the $\mathrm{B}$ and $\mathrm{M}$ segments. Due to technical limitations, it was not possible to carry out those measurements on the $\mathrm{B} 0$ and $\mathrm{T}$ (inability to fit the measuring chamber on the B0 segment without damaging the structure of the leaf basis and to cover the whole chamber area on the $\mathrm{T}$ segments). Full details on the methods are available on Additional file 1 and the results are shown in Figures S4 and S5 (Additional file 1).

The photosynthetic response to light revealed significant differences between leaf segments. The leaf B segment showed light saturation under lower light intensities as compared to the M (Figure S4A - Additional file 1), indicating differential photosynthetic capacity among these segments. On the other hand, the initial slope of the light response curve and the PSII yield (Figure S4B Additional file 1) suggested that the photochemistry is similar between the B and M segments. Together, these data revealed a possible metabolic rather than photochemical limitation in carbon fixation among leaf segments. The apparent electron transport rate - ETR (Figure S4C - Additional file 1) also supports this idea. The relation between ETR and photosynthesis -A (Figure S4D - Additional file 1) represents the amount of electron transport through PSII per $\mathrm{CO}_{2}$ fixed and increased values suggest an activation of alternative electron sinks such as the Mehler reaction and nitrogen (N) metabolism [50].
Photosynthetic response to $\mathrm{CO}_{2}$ was used to estimate some biochemical traits and indicated that the previously mentioned metabolic limitation was caused by differences in PEPcase activity and not RubisCO (Figure S5B and S5C - Additional file 1). Although total carbon content was similar between leaf segments (Fig. 1a), there were significant differences in carbon isotope discrimination among them (Fig. 1b). Carbon isotope discrimination has been used to characterize $C_{4}$ photosynthetic responses in plants growing under diverse environments and stresses [51-56]. $C_{3}$ plants have lower $\Delta^{13} \mathrm{C}$ than $\mathrm{C}_{4}$ plants, mainly because PEPcase has lower discrimination for ${ }^{13} \mathrm{C}$ as compared to RubisCO [57]. Carbon isotope discrimination showed that the $\mathrm{B} 0$ and $\mathrm{B}$ segments presented higher $\Delta^{13} \mathrm{C}$ than $\mathrm{M}$ and $\mathrm{T}$. The $\Delta^{13} \mathrm{C}$ variation in $\mathrm{C}_{4}$ plants is related to radiation intensity in maize, Miscanthus giganthus and Flaveria bidentis, which displayed higher $\Delta^{13} \mathrm{C}$ when cultivated under low light when compared to leaves exposed to high light [58-61]. This difference has been usually interpreted as a result of the leakiness or due to an inefficient $\mathrm{C}_{4}$ photosynthetic pathway. Nevertheless, the metabolic difference between leaf segments in sugarcane cannot be associated with leakiness that varied from $0.034 \pm 0.013$ to $0.031 \pm 0.009$ at $\mathrm{B}$ and $\mathrm{M}$, respectively. In addition, the $\mathrm{B}$ segment presented a lower $k$ when compared to the $\mathrm{M}$ segment (Figure S5C - Additional file 1), corroborating to the fact that the $\mathrm{B}$ has a less

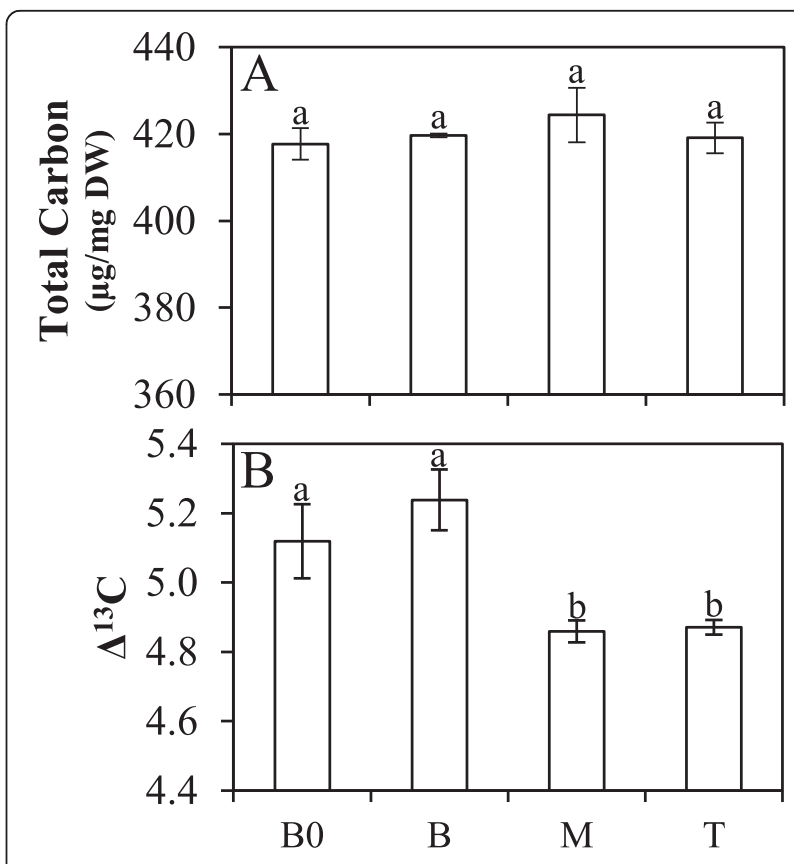

Fig. 1 Total carbon quantification (a) and carbon isotope discrimination (b) in sugarcane leaf segments: Base "zero" (BO), Base (B), middle (M) and tip (T) sugarcane leaf segments. Letters indicate statistical significance using ANOVA followed by post hoc Student $t$-test $(n=5 ; p \leq 0.05)$ 
efficient $\mathrm{C}_{4}$ biochemistry than the $\mathrm{M}$ and $\mathrm{T}$ segments. Interestingly, while $\mathrm{B} 0$ and $\mathrm{B}$ had higher $\Delta^{13} \mathrm{C}$ than the rest of the leaf, the $B$ segment showed lower photosynthetic rate (Figure S4A - Additional file 1) but similar PSII yield as compared to the M segment (Figure S4B Additional file 1). This reinforces our interpretation that the $\mathrm{C}_{4}$ biochemical inefficiency in basal portions is higher than in the other parts of the leaf.

In order to investigate possible changes in PEPcase and RubisCO among the segments, immunoblotting and enzyme activity assays were performed. Although immunoblotting of leaf extracts showed some variation between biological replicates from the same segment, differences in PEPcase protein abundance were observed (Fig. 2a) with the highest amount being detected at the $\mathrm{M}$ segment. In addition, in vitro PEPcase activity was significantly higher at the $\mathrm{M}$ in comparison to the other segments (Fig. 2a), validating the in vivo $k$ estimation

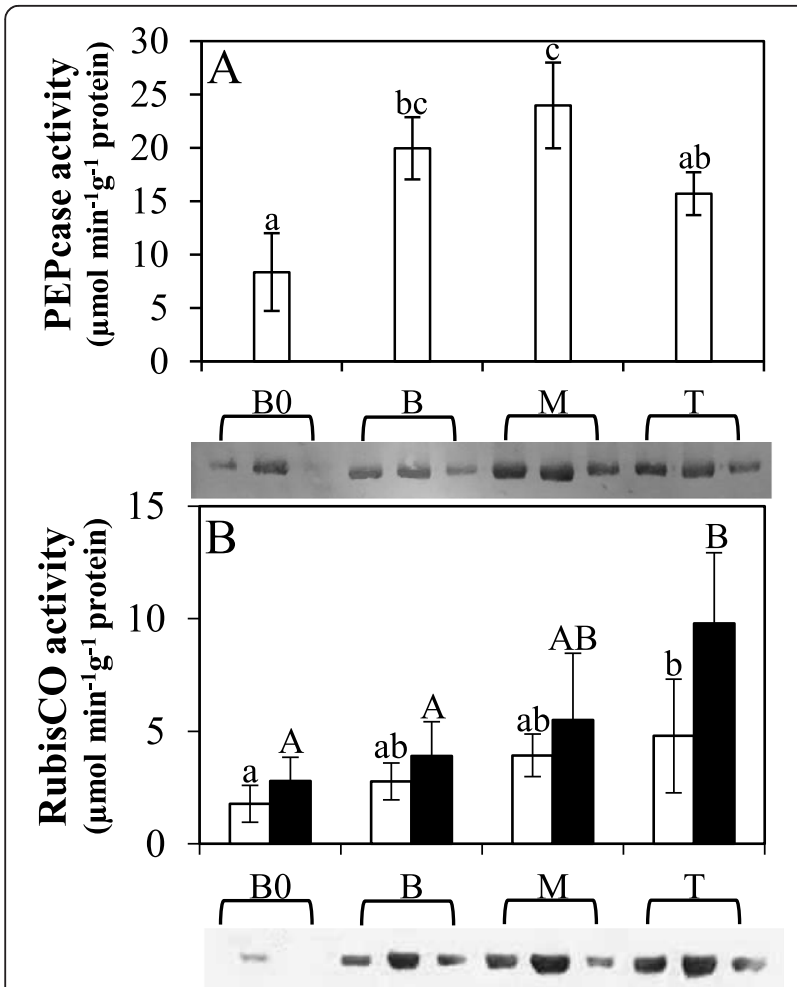

Fig. 2 Changes in activity and protein amount of carboxylation enzymes in sugarcane leaf segments: Base "zero" (B0), Base (B), middle (M) and tip (T). (a) Phosphoenolpyruvate carboxylase (PEPcase). Letters indicate statistical significance using ANOVA followed by post hoc Student $t$-test $(n=4 ; p \leq 0.05)$; (b) Ribulose-1,5bisphosphate carboxylase/oxygenase (RubisCO). White bars represent initial activity and black bars total activity. Lower case letters and capital letters indicate statistical significance using ANOVA followed by post hoc Student $t$-test $(n=4 ; p \leq 0.05)$ on initial and total activity, respectively. For the immunoblots the same amount of protein $(100 \mu \mathrm{g})$ was loaded for each sample. Three independent biological replicates are shown for each segment
(Figure S5C - Additional file 1). For RubisCO, the B0 segment was identified as the one with the lowest amount of both protein and activity (Fig. 2b). There was a tendency of increasing RubisCO activity along the leaf blade, but statistical significance was only detected between the $\mathrm{B} 0$ and $\mathrm{T}$ segments. The RubisCO activation state was also calculated as the ratio of initial activity to total activity but no substantial differences were detected among segments $(0.63 \pm 0.18,0.70 \pm 0.25,0.75 \pm 0.30$, $0.54 \pm 0.16$ at B0, B, M and T, respectively), corroborating also with in vivo $\mathrm{V}_{\max }$ estimation (Figure $\mathrm{S} 5 \mathrm{~B}$ Additional file 1).

The number of stomata between leaf segments was similar when considering the adaxial and abaxial surfaces (Figure S6 - Additional file 1). This indicates that stomata density does not contribute to the variations observed at photosynthetic rates (Figure S5A). Although some studies reveal that stomatal density has a positive correlation with photosynthesis [62], differences in photosynthesis along leaf blades of several $C_{3}$ and $C_{4}$ grasses were not explained by stomata density [63].

$\mathrm{N}$ content increased along the leaf length and was higher at the $\mathrm{M}$ and $\mathrm{T}$ segments (Fig. $3 \mathrm{a}$ ). These results are very similar to those found in the plant canopy, where the bottom leaves have lower $\mathrm{N}$ concentration than upper ones due to variations in light availability $[16,64]$. However, $N$ investment on photosynthetic machinery was similar, with photosynthetic nitrogen-use efficiency (PNUE) varying between $1.08 \pm 0.17 \mathrm{~mol} \mathrm{~mol}^{-1} \mathrm{~h}^{-1}$

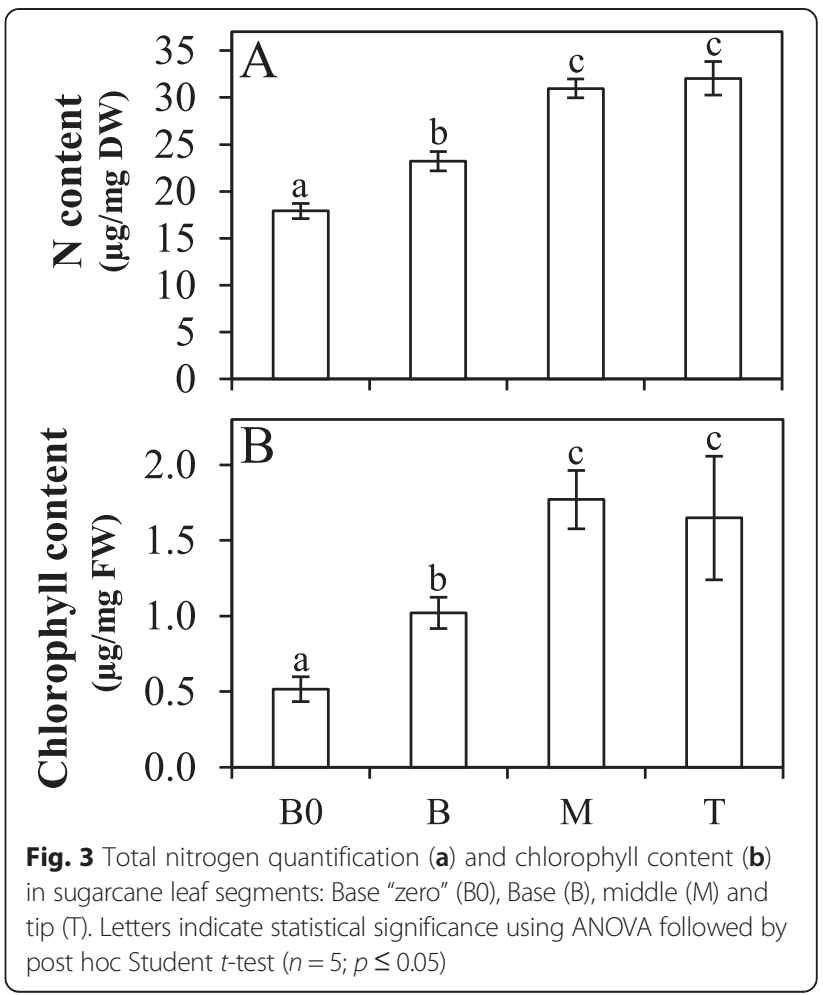


at the B segment and $1.09 \pm 0.14 \mathrm{~mol} \mathrm{~mol}^{-1} \mathrm{~h}^{-1}$ at the $\mathrm{M}$ segment. Chlorophyll concentration was also higher on the $\mathrm{M}$ and $\mathrm{T}$ segments in comparison to the $\mathrm{B} 0$ and B (Fig. 3b), but those differences were not sufficient to bring about changes in photochemical activity among the leaf segments (Figure S4B and S4C - Additional file 1).

The quantification of soluble sugars revealed a clear tendency of higher glucose, fructose and sucrose concentrations at the $\mathrm{T}$ when compared to the other segments (Table 1). Although the evaluated photosynthetic parameters showed significant differences between the $B$ and $M$ segments, they were not contrasting in terms of sugar content, the end products of photosynthesis. However, one should consider that sugar concentration in leaves is affected not only by current photosynthesis but also by its dynamic of consumption and exportation. Interestingly, metabolite profiling in fifteen $1 \mathrm{~cm}$-long maize leaf segments showed that glucose and fructose levels were higher in regions close to the base and decreased along the leaf blade towards the tip. Sucrose, in contrast, presented a distinct behavior, with higher levels in segments close to the base and tip and lower levels in the middle regions [48]. Myo-inositol showed a clear gradient of accumulation from $\mathrm{B} 0$ to the $\mathrm{T}$ segment (Table 1). Myo-inositol has a central role in plant metabolism and can be used as precursor for the synthesis of phosphatidylinositol, compatible solutes (such as raffinose-family oligosaccharides) and cell wall polysaccharides [65]. In maize leaves, myo-inositol levels present the same trend observed in sugarcane leaves [48]. Together, our results suggest that the distribution of sugars along the sugarcane leaf is distinct from maize. However, any comparison between the two plant species must be regarded with caution. First, the age of the plants in the two studies are very different: while Wang et al. [48] have analyzed nine days-old maize leaves, the sugarcane plants in this study were two-months old. Second, the authors used the third leaf (from bottom to top) for maize, while for sugarcane we used the first leaf (from top to bottom) with the dewlap fully exposed.

\section{Transcriptional profiling}

\section{RNA-seq de novo transcript assembly and annotation}

The mRNAs from the segments (B0, B, M and T) of four individuals were sequenced and on average 33.8 million paired-end 100-bp strand-specific reads were obtained per segment and per individual (after quality trimming of the reads), with a total of 380 million high quality reads (after removal of contaminants, ribosomal RNA, mitochondrial and plastid reads). High quality reads were assembled with Trinity (version r20140717) as described in Methods. These data comprise 250,035 correctly oriented transcripts or contigs that were kept for further analysis, as they appear to originate from viridiplantae or did not had any hits to nucleotide sequences in the NCBI databases (Additional file 2). These 250,035 contigs were grouped into 135,481 loosely defined genes that could represent paralogous copies of the genes or copies from the homologous genomes. The average contig length was 878 bp with approximately $28 \%$ of the contigs over $1 \mathrm{Kbp}$ long, and the smallest contig with $283 \mathrm{bp} ; 27.3 \%(68,367)$ of the assembled contigs appear to code for proteins. 132,665 (53 \%) contigs were annotated with Trinotate and 64,813 of these had Gene Ontology (GO) terms assigned (Additional file 3). The full set of de novo assembled contigs was compared to the full set of Sorghum bicolor proteins and transcripts (v2.1 Phytozome), using transrate (v1.0.1). On one hand, around $31 \%$ of the sugarcane contigs had a high confidence predicted homologue (Conditional Reciprocal Best BLAST, CRBB) in S. bicolor, when compared to the sorghum proteins, and $40 \%$ when compared to the sorghum transcripts. On the other hand, $60 \%$ of the sorghum proteins and $65 \%$ of the sorghum transcripts have CRBBs in sugarcane. We further inspected our transcriptome assembly using CEGMA, which has a set of 248 highly conserved eukaryotic genes that are usually present as single copy genes in many species. We were able to detect $72.18 \%$ of these genes as complete proteins or $77.82 \%$ when considering partial hits, with 3.63 copies of each gene on average. We have assigned 7,270 contigs into 333 KEGG pathways (Additional file 4) and identified 2,889 contigs belonging to 72 transcription associated families, i.e., transcription factors or other

Table 1 Quantification of soluble sugars

\begin{tabular}{lllll}
\hline Segment/Sugar & sucrose & glucose & fructose & myo-inositol \\
\hline Base "0" & $15.05 \pm 2.01^{\mathrm{a}}$ & $0.53 \pm 0.21^{\mathrm{a}}$ & $0.25 \pm 0.06^{\mathrm{a}}$ & $165.93 \pm 18.28^{\mathrm{a}}$ \\
Base & $16.93 \pm 6.15^{\mathrm{a}}$ & $0.78 \pm 0.09^{\mathrm{a}}$ & $0.11 \pm 0.05^{\mathrm{a}}$ & $258.76 \pm 25.69^{\mathrm{b}}$ \\
Middle & $24.03 \pm 7.63^{\mathrm{ab}}$ & $1.69 \pm 0.66^{\mathrm{a}}$ & $0.37 \pm 0.18^{\mathrm{a}}$ & $439.48 \pm 37.87^{\mathrm{c}}$ \\
Tip & $29.99 \pm 6.84^{\mathrm{b}}$ & $4.50 \pm 1.13^{\mathrm{b}}$ & $2.69 \pm 0.95^{\mathrm{b}}$ & $953.45 \pm 62.33^{\mathrm{d}}$ \\
\hline
\end{tabular}

Values shown are mean $\pm \mathrm{SD}(n=5)$ and referred to $\mu \mathrm{mol} \mathrm{g}^{-1} \mathrm{FW}$, except for myo-inositol (nmol g ${ }^{-1} \mathrm{FW}$ ). Letters indicate statistical significant difference between leaf segments using ANOVA followed by post hoc Student $t$-test $(p \leq 0.05)$ 
transcriptional regulators, by applying the procedure described in Perez-Rodriguez et al. [66] (Additional file 5). We also identified 38,399 groups of orthologous genes between the grasses Saccharum spp. (de novo assembled transcriptome), Oryza sativa, Zea mays, Sorghum bicolor and Setaria italica (all protein datasets were downloaded from Phytozome) using OrthoMCL (inflation value $1.5) ; 10,288$ groups of orthologous genes are shared between the five species, more importantly 15,840 groups of orthologues are shared between sugarcane and any of the other grasses representing 36,629 sugarcane transcripts, with 7,339 groups of orthologues present exclusively in sugarcane (Figure S7- Additional file 1). These results show the overlap in protein space between these species, and highlights that our de novo sugarcane transcriptome assembly recovered a large proportion of the genes that are present in grasses (Additional file 6).

\section{Analysis of transcript abundance and differential expression analyses}

In this study, we aimed to generate a transcriptome resource to evaluate the developmental dynamics along the sugarcane leaf. For that, we estimated transcript abundances using eXpress, read counts were analyzed in edge $\mathrm{R}$ and normalized using the "trimmed mean of $\mathrm{M}$ values" (TMM) method [67]. Comparisons between segments were performed subtracting distal from basal segments originating the three orthogonal contrasts: Base vs. Base "zero" (B-B0); Middle vs. Base (M-B); Tip vs. Middle (T-M) (Tables S1-S3 - Additional file 7). For this analysis we have summarized the read counts at the level of genes as defined above ( $\mathrm{R}$ code and read counts per gene per sample are available as Additional file 8). The representation of the contrasts and the number of differentially expressed (DE) genes are depicted on Fig. 4. The Venn diagram shows that the leaf undergoes a drastic transcriptional rearrangement along the developmental gradient (Fig. 5). This is even more evident when considering the number of DE genes shared among the contrasts (Fig. 5). Only 14 genes were present in all contrasts (Fig. 5 and Table 2) and almost $72 \%$ of all DE genes were present only in the T-M contrast (Fig. 5). This is in agreement with Majeran et al. [45] and Pick et al. [49], who found higher the amount of transcripts and proteins toward the tip of maize leaves. We observed the same pattern on sugarcane, not only on transcripts number, but also by extracting and quantifying protein content (Figure S8 - Additional file 1).

Considering the 14 differentially expressed genes that are present in all contrasts, we were able to identify four expression patterns along the leaf developmental gradient (Figure S9 - Additional file 1). The first pattern (Figure S9A - Additional file 1) is composed by the

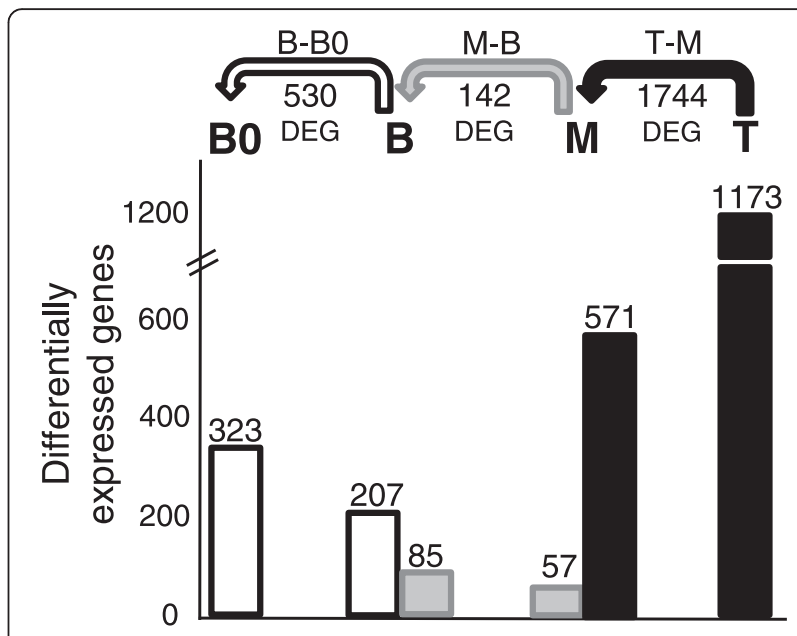

Fig. 4 Representation of the RNA-seq contrasts between segments. Each segment was compared against the previous one (basal/distal length) originating three contrast: Base - Base "zero" (B-BO); Middle Base (M-B); Tip - Middle (T-M). The number of differentially expressed genes (DEG) is depicted under the arrows representing the contrasts. Number of genes overexpressed on each segment considering different contrasts is shown above the graphic bars

transcriptional factor TCP5 (SP803280_c109776_g3) that monotonically increased its expression from B0 to $\mathrm{T}$ segments. Members of this family are involved with leaf morphogenesis and differentiation [68-70], arrest of cell division [71], leaf elongation [72] and auxin response [73]. To date, there is no information on the role of TCP5 in $\mathrm{C}_{4}$ plants and its expression profile in our dataset suggests that this gene can be an important player during leaf development.

Ten genes from the second pattern (Figure S9B Additional file 1) presented an opposite behavior, with

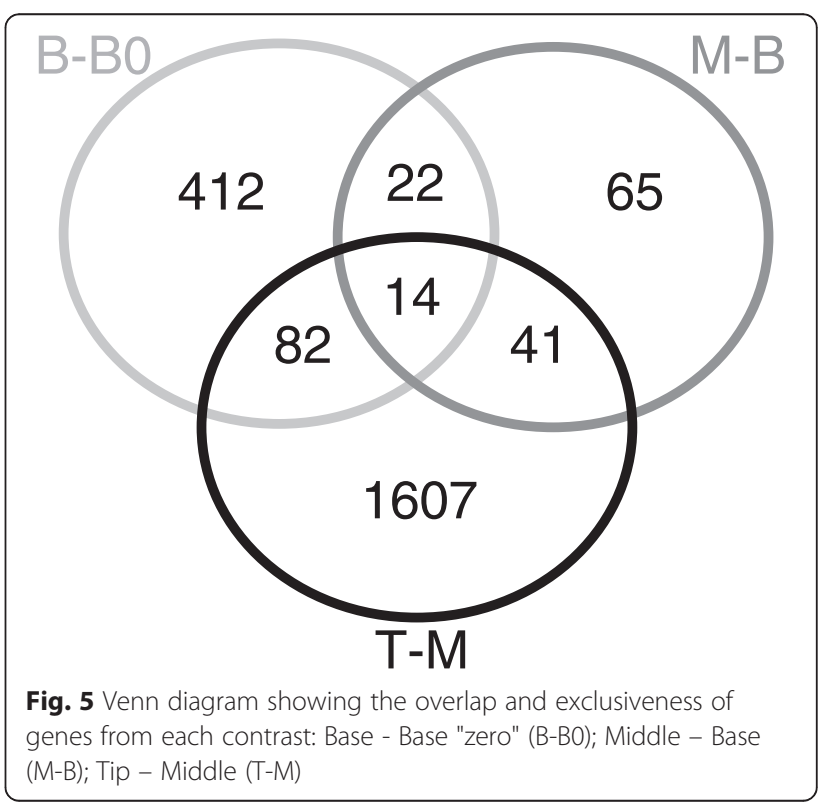


Table 2 Genes identified in all contrasts [Base - Base "zero" (B - B0); Middle - Base (M-B); Tip - Middle (T-M)]

\begin{tabular}{|c|c|c|c|c|c|}
\hline \multirow[b]{2}{*}{ Gene ID } & \multicolumn{3}{|c|}{ Contrast } & \multirow[b]{2}{*}{ Annotation } & \multirow[b]{2}{*}{ Validation } \\
\hline & B-BO & $M-B$ & P-M & & \\
\hline SP803280_c109776_g3 & 2.48 & 1.70 & 2.07 & Transcription factor TCP5 & 0.98 \\
\hline SP803280_c88088_g1 & -1.10 & -2.11 & -1.71 & $\mathrm{~N} / \mathrm{l}$ & 0.26 \\
\hline SP803280_c108434_g2 & -1.50 & -1.60 & -1.90 & Protein trichome birefringence & 0.27 \\
\hline SP803280_c113688_g1 & -1.51 & -2.24 & -1.49 & 4-hydroxyphenylacetaldehyde oxime monooxygenase & 0.96 \\
\hline SP803280_c103567_g1 & -1.58 & -1.89 & -1.54 & $\mathrm{~N} / \mathrm{I}$ & 0.62 \\
\hline SP803280_c110116_g1 & -1.62 & -2.01 & 2.11 & Cysteine-rich repeat secretory protein 38 & 0.56 \\
\hline SP803280_c99583_g1 & -1.92 & -2.74 & -3.89 & $\mathrm{~N} / \mathrm{l}$ & 0.94 \\
\hline SP803280_c109581_g5 & -2.01 & -2.96 & 2.13 & Methylsterol monooxygenase 1-2 & 0.71 \\
\hline SP803280_c87779_g1 & -2.33 & -2.12 & -2.12 & $\mathrm{~N} / \mathrm{l}$ & 0.42 \\
\hline SP803280_c81421_g1 & -2.37 & -1.81 & -2.87 & Cell wall / vacuolar inhibitor of fructosidase 2 & 0.56 \\
\hline SP803280_c114207_g1 & -2.56 & -2.83 & -2.88 & Cycloartenol-C-24-methyltransferase 1 & 0.79 \\
\hline SP803280_c100769_g2 & -2.66 & -3.24 & -3.62 & $\mathrm{~N} / \mathrm{I}$ & 0.99 \\
\hline SP803280_c70793_g2 & -2.74 & -2.01 & -1.97 & $\mathrm{~N} / \mathrm{l}$ & 0.87 \\
\hline SP803280_c116667_g1 & -3.61 & 5.54 & 2.25 & Naringenin,2-oxoglutarate 3-dioxygenase & 0.69 \\
\hline
\end{tabular}

The number bellow each contrast indicates the log Fold Change in the respective contrast

Validation column indicates the average coefficient of determination $\left(R^{2}\right)$ between logCPM (from RNA-seq data) and log $\Delta C t$ ( $q R T-P C R$ data)

high expression at B0 segment and decreasing expression towards the T segment. Among them, we can point out the trichrome birefringence gene (SP803280_c108434_g2), which is important for o-acetylation of cell walls required for cellulose biosynthesis [74-76], and the gene encoding a 4-hydroxyphenylacetaldehyde oxime monooxygenase (SP803280_c113688_g1) involved in the production of a cyanogenic glycoside called dhurrin [77, 78]. This compound has been related to drought tolerance in sorghum [79] and to biotic stress response [80]. Interestingly, dhurrin can also be regarded as an $\mathrm{N}$ storage molecule that peaks on early development stages in sorghum [81]. Genes involved in carbohydrate and sterol metabolism were also classified into this pattern: the cell wall and vacuolar inhibitor of fructosidase 2 (SP802180_c81421_g1) responsible for post-transcriptional silencing of fructosidase activity and important in the development of photosynthetic apparatus, stress response and sugar signaling $[82,83]$; and the cycloartenol-C-24-methyltranferase 1 (SP803280_c114207_g1- also known as SMT1) that catalyzes the initial step in biosynthesis of sterol, a class of compound with several regulatory roles in plant development [84]. SP803280_c87779_g1 code for an invertase/pectin methylesterase inhibitor ortholog of LOC_Os08g01670.1 and LOC_Os12g18560.1 in rice [85], and thus might be involved in the remodeling of the plant cell wall. SP803280_c100769_g2, coding for a dirigent protein ortholog to LOC_Os01g24960.1 and LOC Os01g25030.1 in rice, involved in lignin biosynthesis [86]. An additional gene SP803280_c103567_g1 with orthologues in setaria, maize and sorghum, but not in rice is of unknown function, while SP803280_c88088_g1 and SP803280_C99583_g1 do not appear to code for proteins. In summary, genes that presented the second pattern are involved in early developmental processes and cell wall modification, corroborating with their expression on the most basal segment.

The pattern 3 was comprised by genes with lower expression at the M segment (Figure S9C - Additional file 1), like those encoding methylsterol monooxygenase 1-2 (SP803280_c109581_g5) and cysteine-rich repeat secretory protein 38 (SP803280_c110116_g1). Methylsterol monooxygenase is involved in sterol metabolism [87], important for membrane fluidity and membrane interaction with proteins and lipids [88, 89]. Arabidopsis has more than 100 genes coding for cysteine-rich repeat proteins making them one of the largest gene families. However, their role on plant metabolism is still to revealed [90].

Pattern 4 (Figure S9D - Additional file 1) is characterized by lower expression at B segment and had only one gene, encoding a naringenin, 2-oxoglutarate 3dioxygenase (SP803280_c116667_g1). This protein participates in the flavonoids biosynthesis [91], important for UV protection, defense against pathogens and pests, regulation of auxin transport and pigmentation [92].

All those 14 genes were also used to validate RNAseq data by qRT-PCR using three biological replicates (different from those used for the RNA-seq experiment). The average coefficient of determination $\left(R^{2}\right)$ between $\log C P M$ and $\log \Delta$ Ct was 0.70 (Table 2). Genes with low expression values (SP803280_c103567_g1, SP803280_c108434_g2, SP803280_c110116_g1, SP803280_ 
c116667_g1, SP803280_c70793_g2) had the lowest $R^{2}$ correlation as reported before for genes with similar expression levels [93-95]. However, it is worthwhile mentioning that despite these low $R^{2}$ values, the general expression profile obtained by qRT-PCR resembled those obtained by RNASeq. We cannot ignore the pitfalls and artefacts of each technique, but one possible explanation might be the fact that we have a de novo transcriptome assembly of a crop with a complex polyploid genome that has not been sequenced yet. This represents an extra layer of difficulty when designing primers for qRT-PCR, as it is not possible to distinguish between all the alleles and paralogues, increasing the variability of qRT-PCR data.

We were also interested in comparing the transcriptional profile of sugarcane (this study) to the one observed in another $\mathrm{C}_{4}$ species, maize (recently published by Wang et al [48]). We compared the expression of over 2,390 one-to-one orthologous genes between sugarcane and maize, identified by OrthoMCL (Fig. 6), in a similar fashion as described by Wang et al. [48] (Data matrices and $\mathrm{R}$ code are available as Additional file 9). The expression profiles during leaf development between these two species were substantially different as the whole developmental gradient of the sugarcane leaf fits better into the distal half of the maize leaf (Spearman correlation coefficient higher than 0.6 - Fig. 6).

\section{Enrichment of gene ontology terms}

A GO enrichment analysis was performed by categorizing differentially regulated genes into GO biological processes (Tables S4-S9 - Additional file 10). Each contrast was divided into two gene lists in order to evaluate the enrichment of biological processes. For instance, the contrast B-B0 was separated into positive $\log \mathrm{FC}$ - genes more expressed at the $\mathrm{B}$ segment - and negative log $\mathrm{FC}$ - genes more expressed at the B0 segment). Considering the contrast $\mathrm{B}$ - $\mathrm{B} 0$, the most significant biological processes in $\mathrm{B} 0$ segment were those involved with cell wall organization and biosynthesis (e.g. GO IDs 71669, 71554, 9664, 9832 and 42546). It is noteworthy that wax metabolic processes (GO ID 10166), anatomical structure development (GO ID 48856), developmental process (GO ID 32502) and leaf formation (GO ID 10338) were also enriched terms in this segment (Table S4 - Additional file 10). In the B segment, the most significant GO terms were flavonoid biosynthetic and metabolic processes (GO ID 9813 and 9812), redox process (GO ID 55114), cellular response to high light (GO ID 71486) and lipid metabolic process (GO ID 6629) (Table S5 - Additional file 10).

The GO enrichment analysis indicated that in the contrast M-B, genes related to DNA modification (GO IDs 6334, 34728, 31497, 71824, 65004, 6333, 16126, 6323) and N metabolism (GO ID 10243 and 1901698) were more expressed in the B segment (Table S6 - Additional file 10). In the $M$ segment, only two GO IDs were enriched (9813, 9812), both related to flavonoid metabolism (Table S7 - Additional file 10).

Interestingly, the largest amount of $\mathrm{DE}$ genes was found between the $M$ and $T$, the segments that demonstrated the most similar behavior according to the physiological data. On the other hand, the $\mathrm{M}$ and $\mathrm{B}$

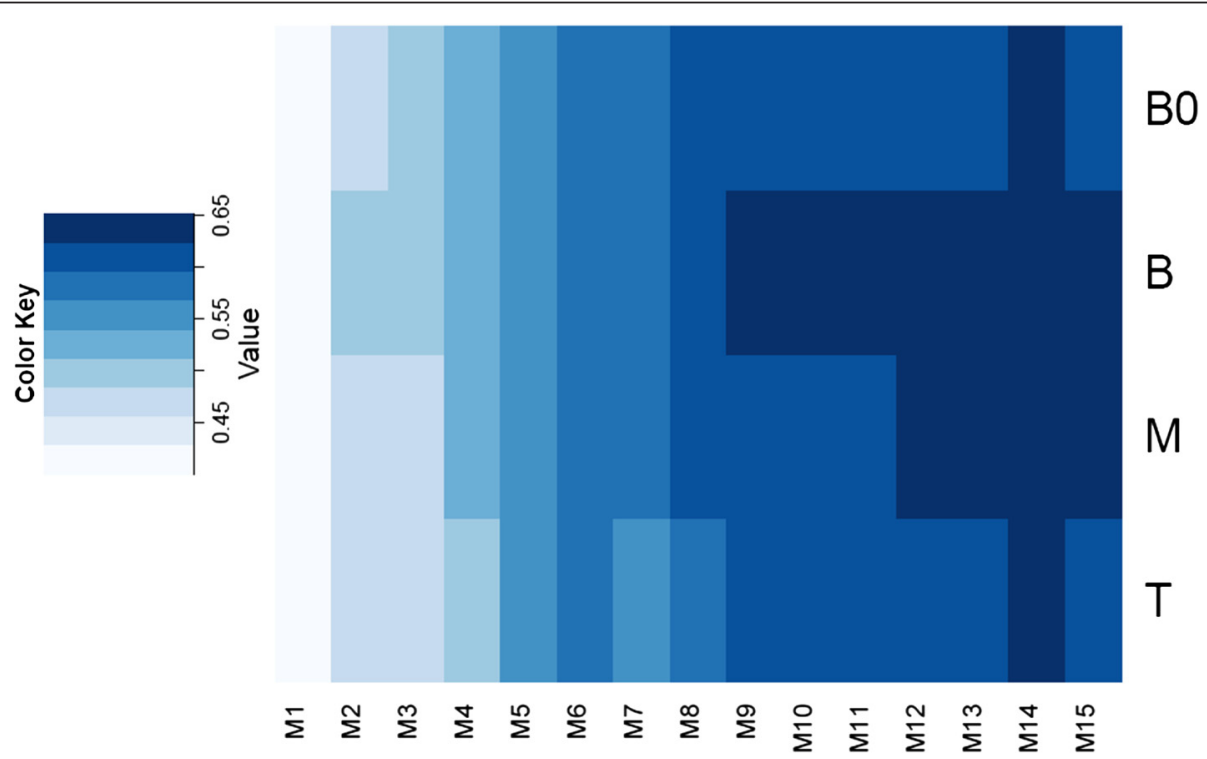

Fig. 6 Spearman correlation between fifteen segments along developmental gradient of maize leaves (M1 to M15 - published by [48]) and the four sugarcane leaf segments (BO, B, M and T - this study) 
showed the smallest amount of DE genes in spite of their differences in physiological behavior, especially photosynthetic capacity, carbon isotope discrimination and $\mathrm{N}$ content. Considering the T-M contrast, the most overrepresented GO IDs in the $\mathrm{M}$ were those related to photosynthesis and redox processes (15979, 55114, 19684) (Table S8 - Additional file 10). The T segment presented the highest number of enriched terms related to amino sugar catabolic process (GO ID 46348), ion transport (GO ID 6811), transmembrane transport (GO ID 55085), zinc ion transport (GO ID 6829), cation transport (GO ID 6812) and anion transport (GO ID 6820) (Table S9 - Additional file 10).

\section{Biochemical pathways}

\section{Photosynthesis-related genes}

It is already known that the $\mathrm{C}_{4}$ biochemical pathway is transcriptionally regulated $[96,97]$ under developmental [98] and light [99] control. In our study, only one NADP-dependent malic enzyme (SP803280_c89172_g1) was differentially expressed in the B0-B contrast (Table $\mathrm{S} 1$ - Additional file 7). This indicates that $\mathrm{CO}_{2}$ concentrating mechanism is still under development in the B0 segment, which is less exposed to light than the other ones. Two phosphoenolpyruvate carboxykinases (PEPCK - SP803280_c92961_g1 and SP803280_c92945_g1) were more expressed at the B segment (contrast M-B, Table S2 - Additional file 7). This enzyme has been reported as an important regulator of the aspartate metabolism in bundle sheath cells where aspartate is decarboxylated to PEP by PEPCK and $\mathrm{CO}_{2}$ supplied to the Calvin-BensonBrassham cycle [100].

Nevertheless, the contrast T-M showed the highest amount of photosynthesis related genes (Table 3), and the majority of them was more expressed at the $M$ segment such as enzymes of the Calvin-Benson-Brassham cycle and proteins associated with chlorophyll and photosystems. Interestingly, the expression of four PEPcase genes was higher at the $\mathrm{T}$ segment in comparison to the $\mathrm{M}$ segment. This finding corroborates with the qPCR data reported by Li et al. [44], in which the transcript level of one PEPcase increasing towards the tip of maize leaves. However, our immunoblotting and enzymatic assays revealed greater content and activity at the $\mathrm{M}$ segment (Fig. 2) and decrease in both activity and content at the T. Additionally, PEPcase is known to undergo post-transcriptional and post-translational modifications $[98,101,102]$ and a recent study demonstrated that the Spearman rank correlation $\left(R_{S}\right)$ between mRNA and protein abundance for genes related to photosynthesis on different sections of maize leaf was 0.581 on average [103], indicating that PEPcase expression profile may not be an indication of more photosynthetically active tissue. One NADP-dependent malic enzyme was also more expressed at the T segment (SP803280_c89172_g1), corroborating with other reports that indicated its increase towards the tip [104, 105].

The gene encoding a glyceraldehyde-3-phosphate dehydrogenase (SP803280_c104535_g4) was expressed at the $\mathrm{T}$ segment and the expression of the Arabidopsis homologue is increased under several stress conditions such as heat, anoxia and high sucrose concentration [106]. In fact, the T segment has lower leaf water content (Figure S10 - Additional file 1), which may lead to stress responses similar to oxidative stress in a similar fashion described by Pick et al. [49] for maize leaf tips. Accordingly, many genes related to oxidative stress were expressed at the $\mathrm{T}$ segment.

\section{Sugars}

Genes related to carbohydrate metabolism are depicted on Table 4. Analysis of the B-B0 contrast revealed that two genes (SP803280_c111302_g1 and SP803280_c117830_g1) more expressed at the B0 segments encoded proteins involved in the synthesis of trehalose-6-phosphate (Tre6P), the phosphorylated intermediate of the non-reducing sugar trehalose. Tre6P is considered a signal of sucrose availability and acts to maintain sucrose concentration within a proper range $[107,108]$. We have not quantified the levels of Tre6P in our experiments, but sucrose content was similar at B0, B and M segments (Table 1). The above-mentioned genes encode Tre6P synthase class II proteins (Figure S11 - Additional file 1), which in Arabidopsis thaliana do not have catalytic activity and are of unknown function [109]. In addition, a transcript related to sucrose metabolism (sucrose synthase 2 - SP803280_c114621_g2) was also induced in the B0 segment.

In the M-B contrast only one gene encoding an invertase (SP803280_c100721_g1) was more expressed in the $\mathrm{M}$ segment. The vast majority of $\mathrm{DE}$ genes related to sugars was observed in the contrast T-M (Table 4). Several genes involved in starch and sucrose metabolism and interconversion of hexoses-phosphate were upregulated in the $\mathrm{T}$ segment. In addition, a gene coding for an inositol-3-phosphate synthase (SP803280_c101982_g1), a key enzyme in the conversion of glucose to myo-inositol [110], was 2-fold more expressed in the T relative to $M$. Such finding is in agreement with the concentration of this sugar alcohol at the T segment (Table 1). Two purple acid phosphatase 2 genes (SP803280_c99372_g1 and SP803280_c94862_g2), responsible for the dephosphorylation of myo-inositol hexakisphosphate (a phosphorus storage molecule) have been upregulated in the $\mathrm{T}$ segment whereas only one gene (SP803280_c96835_g1) was more expressed in the $\mathrm{M}$ segment. Furthermore, phosphoinositide phospholipase C4 (SP803280_c115744_g2) and phospholipase D (SP803280_c113920_g1) which 
Table 3 Photosynthesis related genes identified on each contrast

\begin{tabular}{|c|c|c|}
\hline GenelD & Annotation & LogFC \\
\hline \multicolumn{3}{|l|}{ Contrast B-BO } \\
\hline SP803280_c89172_g1 & NADP-dependent malic enzyme & -1.28 \\
\hline SP803280_c102133_g1 & Fructose-bisphosphate aldolase, chloroplastic & 1.36 \\
\hline \multicolumn{3}{|l|}{ Contrast M-B } \\
\hline SP803280_c92945_g1 & Phosphoenolpyruvate carboxylase kinase 1 & -1.70 \\
\hline SP803280_c92961_g1 & Phosphoenolpyruvate carboxylase kinase 1 & -2.16 \\
\hline \multicolumn{3}{|l|}{ Contrast T-M } \\
\hline SP803280_c110449_g1 & Ribose-5-phosphate isomerase 4, chloroplastic & -3.87 \\
\hline SP803280_c67360_g1 & Photosystem II reaction center W protein, chloroplastic & -3.62 \\
\hline SP803280_c95106_g1 & Chlorophyll a-b binding protein, chloroplastic & -3.37 \\
\hline SP803280_c92288_g1 & NADP-dependent malic enzyme, chloroplastic & -2.87 \\
\hline SP803280_c102650_g1 & Magnesium-chelatase subunit Chll, chloroplastic & -2.38 \\
\hline SP803280_c99238_g1 & Chlorophyll a-b binding protein CP24 10B, chloroplastic & -2.33 \\
\hline SP803280_c104535_g4 & Glyceraldehyde-3-phosphate dehydrogenase GAPB, chloroplastic & -2.32 \\
\hline SP803280_c103134_g1 & Phosphoenolpyruvate carboxylase 3 & -2.28 \\
\hline SP803280_c80781_g1 & Photosystem I reaction center subunit Vl, chloroplastic & -2.27 \\
\hline SP803280_c97299_g1 & Carbonic anhydrase, chloroplastic & -2.19 \\
\hline SP803280_c92767_g1 & Ribulose bisphosphate carboxylase small chain, chloroplastic & -2.17 \\
\hline SP803280_c92767_g1 & Ribulose bisphosphate carboxylase small chain, chloroplastic & -2.17 \\
\hline SP803280_c96992_g1 & Photosystem I reaction center subunit XI, chloroplastic & -2.04 \\
\hline SP803280_c94064_g1 & Photosystem II reaction center PSB28 protein, chloroplastic & -2.03 \\
\hline SP803280_c86157_g1 & Chlorophyll a-b binding protein 7, chloroplastic & -1.99 \\
\hline SP803280_c104447_g1 & Photosystem II core complex proteins psbY, chloroplastic & -1.99 \\
\hline SP803280_c88331_g1 & Ferredoxin-thioredoxin reductase, variable chain & -1.74 \\
\hline SP803280_c87990_g4 & ATP synthase delta chain, chloroplastic & -1.73 \\
\hline SP803280_c100740_g1 & Photosystem II repair protein PSB27-H1, chloroplastic & -1.65 \\
\hline SP803280_c89062_g1 & Photosystem I reaction center subunit III, chloroplastic & -1.52 \\
\hline SP803280_c95984_g2 & Photosystem II core complex proteins psbY, chloroplastic & -0.98 \\
\hline SP803280_c97299_g2 & Carbonic anhydrase, chloroplastic & -0.73 \\
\hline SP803280_c20755_g1 & Ferredoxin-NADP reductase, leaf isozyme, chloroplastic & -0.63 \\
\hline SP803280_c89172_g1 & NADP-dependent malic enzyme & 1.18 \\
\hline SP803280_c108467_g2 & Phosphoenolpyruvate carboxylase 1 & 1.26 \\
\hline SP803280_c57883_g1 & Phosphoenolpyruvate carboxylase 1 & 1.29 \\
\hline SP803280_c25925_g1 & Phosphoenolpyruvate carboxylase 1 & 1.54 \\
\hline SP803280_c89145_g1 & Phosphoenolpyruvate carboxylase 1 & 1.88 \\
\hline
\end{tabular}

LogFC: Log Fold Change. Positive LogFC indicates more expression at the more basal segment of the contrast; negative LogFC indicates more expression at the most distal segment of the contrast

participate on inositol signaling [111] were more expressed in the $M$ segment.

Although many changes in transcripts related to enzymes of the sugar metabolism have been noticed, we could not directly link transcript abundance to the quantified sugars in most cases. A possible explanation is that other factors are influencing protein activity such as translation efficiency, protein assembly and degradation [112].

\section{Cell wall biosynthesis and cell growth}

Several cell wall related genes were DE in the tested contrasts (Table S10 - Additional file 11), indicating cell wall modification along the leaf developmental gradient. 
Table 4 Sugar-related genes identified on the contrast Tip - Middle (T-M)

\begin{tabular}{|c|c|c|}
\hline GenelD & Annotation & LogFC \\
\hline SP803280_c96835_g1 & Purple acid phosphatase 2 & -3.23 \\
\hline SP803280_c109484_g1 & Alkaline/neutral invertase CINV1 & -2.91 \\
\hline SP803280_c115744_g2 & Phosphoinositide phospholipase C 4 & -2.67 \\
\hline SP803280_c106015_g1 & Fructose-bisphosphate aldolase, cytoplasmic isozyme & -2.36 \\
\hline SP803280_c111302_g1 & Alpha,alpha-trehalose-phosphate synthase [UDP-forming] 8 & -1.48 \\
\hline SP803280_c114621_g2 & Sucrose synthase 2 & -1.29 \\
\hline SP803280_c117830_g1 & Alpha,alpha-trehalose-phosphate synthase [UDP-forming] 5 & -1.17 \\
\hline SP803280_c113920_g1 & Phospholipase D delta & -0.93 \\
\hline SP803280_c117255_g1 & Glucose-6-phosphate isomerase, cytosolic & -0.64 \\
\hline SP803280_c95757_g2 & Pyrophosphate-fructose 6-phosphate 1-phosphotransferase subunit alpha & 0.57 \\
\hline SP803280_c118055_g1 & Alpha-glucosidase & 0.59 \\
\hline SP803280_c85603_g1 & Phosphoglycerate kinase, cytosolic & 0.59 \\
\hline SP803280_c107723_g2 & Beta-fructofuranosidase, insoluble isoenzyme 4 & 0.61 \\
\hline SP803280_c111639_g5 & Phosphoglycerate mutase GpmB & 0.68 \\
\hline SP803280_c114046_g3 & Fructokinase-1 & 0.72 \\
\hline SP803280_c87942_g1 & Alkaline/neutral invertase CINV2 & 0.79 \\
\hline SP803280_c98160_g1 & Sucrose synthase 1 & 0.85 \\
\hline SP803280_c94862_g2 & Purple acid phosphatase 2 & 0.94 \\
\hline SP803280_c105243_g1 & UDP-glucose 6-dehydrogenase 4 & 1.02 \\
\hline SP803280_c101982_g1 & Inositol-3-phosphate synthase & 1.09 \\
\hline SP803280_C99372_g1 & Purple acid phosphatase 2 & 1.15 \\
\hline SP803280_c94306_g1 & Plastidial pyruvate kinase 2 & 1.16 \\
\hline SP803280_c100721_g1 & Alkaline/neutral invertase CINV2 & 1.26 \\
\hline SP803280_c114269_g1 & Soluble starch synthase 3, chloroplastic/amyloplastic & 1.29 \\
\hline SP803280_c107054_g1 & Beta-fructofuranosidase 1 & 1.38 \\
\hline SP803280_c101458_g2 & Aldose 1-epimerase & 1.39 \\
\hline SP803280_c109150_g1 & Beta-fructofuranosidase 1 & 2.63 \\
\hline
\end{tabular}

LogFC: Log Fold Change. Positive LogFC indicates more expression at the T segment; negative LogFC indicates more expression at the $M$ segment

Among all identified genes, the pH-dependent cell wall loosening proteins known as expansins [113] were more expressed in the $\mathrm{B} 0$ (contrast $\mathrm{B}-\mathrm{B} 0$ ) and $\mathrm{T}$ (contrast T-M) segments, indicating that the extreme opposite sides of the sugarcane leaf are under cell wall modification when compared to the other adjacent segments (Figure S12 Additional file 1). COBRA genes have an important role in cellulose synthesis [114], and, together with cellulose synthase genes, were more expressed in the $\mathrm{B} 0$ and $\mathrm{T}$ segments. In the most basal segment (i.e. B0), cellulose synthesis is expected to be part of secondary cell walls and structure of vascular system, whereas in the T segment we assume cell wall modifications due to senescence.

Suberin is a heteropolymer formed by lipid and phenolic compounds $[115,116]$ deposited in the bundle sheath cells [117] and may serve as a physical barrier to avoid $\mathrm{CO}_{2}$ leakiness to the mesophyll cells $[118,119]$. Although suberin biosynthetic and regulatory pathways have not been defined for monocots yet [48], some reports identified few genes putatively involved in those processes $[48,117,120]$. Suberin genes identified in all contrasts are listed at Table S11 (Additional file 11). NAC and MYB transcriptional family members might be involved in regulating secondary cell wall and suberin biosynthesis [121-123]. Most of these genes were up regulated in the $\mathrm{B} 0$ (contrast B-B0 Table S1 - Additional file 10) and in B (contrast M-B Table S2 - Additional file 7) segments and the contrast T-M (Table S3 - Additional file 7) presented different expression patterns, indicating that suberization started at the basal portions of leaves before they become fully photosynthetically active.

\section{Transcription factors}

Our analysis identified 1,057 genes belonging to 72 transcription factors or other transcriptional regulator 
families. Enrichment analysis of each contrast (same as described previously in GO analysis) indicated that very few families, if any, were enriched in each segment. However, we could identify several transcriptional factors differentially expressed among segments (Tables S1-S3 - Additional file 7).

The ARF transcriptional factor family and the AUX/ IAA family of other transcriptional regulators are enriched at the B0 segment (Table S12 - Additional file 12). They are involved in the regulation of auxin responsive genes and have several roles in plant development [124], including leaf vascular differentiation [125]. Several AUX/IAA and ARF genes are more expressed at the B0 (SP803280_c113162_g1, SP8032 80_c111058_g1, SP803280_c94112_g1, SP803280_ c114984_g4) when considering the contrast B-B0. AUX/IAA and ARF are also associated with stomatal development [126]. In maize, 31 members of this family have been identified [127]. We have identified 29 genes belonging to these two families in our RNA-seq dataset, but we are not able to state how many more members there are in sugarcane due the lack of a complete sugarcane genome sequence.

Members of bHLH and MYB families, involved in leaf development, were also more expressed in the B0 segment (Table S12 - Additional file 12). Even though MYB transcriptional factors are already known to regulate leaf development in tobacco [128] and tomato [129], bHLH might play a role in controlling the abaxial-adaxial polarity [130] and stomatal development [131].

In the leaf basis, the TCP family was enriched (Table S13 - Additional file 12) and more expressed at the contrast B-B0 (SP803280_c109776_g3). This family has an important role in developmental processes by regulating cell division in vegetative and reproductive structures. In Arabidopsis, TCP15 modulates cell cycle genes [132] and is involved in leaf development and regulation of auxin and cytokinin homeostasis [133-135].

No transcription factor family was enriched in the $\mathrm{B}$ (M-B contrast) and $\mathrm{M}$ (both $\mathrm{M}-\mathrm{B}$ and T-M contrasts) segments (Tables S14-S16 - Additional file 12). On the other hand, the $\mathrm{T}$ segment was enriched in genes from the NAC family (Table S17 - Additional file 12), which has been associated with senescence in some plant species [136-139].

\section{Nitrogen assimilation and metabolism}

$\mathrm{N}$ assimilation genes were up-regulated at the B0 segment (Table S1 - Additional file 7). Accordingly, Wang et al. [48] have reported that the leaf basal portions are responsible for $\mathrm{N}$ assimilation. The nitrate transporter gene (SP803280_c104238_g2), characterized in the classes of membrane proteins and involved in nitrate transport
[140], was upregulated in the B region. Furthermore, the $\mathrm{N}$ concentration at $\mathrm{B} 0$ was lower than the others. The main genes associated to $\mathrm{N}$ metabolism and assimilation were more expressed in the $\mathrm{M}$ and $\mathrm{T}$ segments (Table S3 - Additional file 7). The genes glutamate synthase (GOGAT; SP803280_c109031_g1) and glutamate dehydrogenase 2 (GDH; SP803280 c111059_g2), involved in glutamate biosynthesis from ammonium ions $[141,142]$ were upregulated in the $\mathrm{M}$ and $\mathrm{T}$ segments, respectively. The genes which participate in $\mathrm{N}$ metabolism from nitrate source, such as nitrate reductase (SP803280_c104238_g2; [143] and ferredoxin-nitrite reductase (SP803280_c107711_g3; [144] were upregulated in the $\mathrm{T}$ segment. These data suggest that $\mathrm{N}$ metabolism and its assimilation are modulated along sugarcane leaf and that these processes are concentrated in more mature regions of sugarcane leaves.

\section{Leaf senescence}

Leaf senescence occurs naturally in the quiescent cells and its onset and progression are controlled by external and internal factors. Factors like age, hormone levels and reproductive growth cause differential gene expression, resulting in macromolecule degradation, such as proteins, lipids, pigments (chlorophyll $a$ and $b$; carotenoids) and nucleic acids [145-147] followed by recycling and mobilization of nutrients [147]. According to the transcriptional profile of different leaf segments, some genes and transcription factors (WRKY and NAC family) associated positively with the senescence pathway [136-139, 148] were overexpressed in the $\mathrm{T}$ segment (Family: NAC, SP803280_c104996_g2) as revealed in the contrast T-M (Table S3 - Additional file 7). The gene for the blue copper-binding protein (SP803280_c94951_g1), considered a senescence associated gene - SAG - [149], had a significant increase in expression level in the $\mathrm{T}$ segment.

In the immature B0 segment, no differential expression of SAGs was noticed (Table S1 - Additional file 7). However, we found a significant expression of gene encodig E3 ubiquitin-protein ligase ATL41 (SP803280_c95253_g2) and E3 ubiquitin-protein ligase UPL5 (SP803280_c109558_g1). These enzymes catalyze polyubiquitination and regulate leaf senescence negatively through ubiquitination and subsequent degradation of WRKY53, a key transcription factor of leaf senescence $[150,151]$. This result suggests that the basal segment is functional and mechanisms of senecence avoidence are active, as expected for a young and immature leaf portion.

There are several genes involved in the chlorophyll degradation pathway [152], and some of them were identified as more expressed in the $\mathrm{T}$ (contrast $\mathrm{T}-\mathrm{M}$, Table S3 - Additional file 7). A first step to chlorophyll degradation is the change of chlorophyll-apoprotein 
complex structure and subsequent enzymatic breakdown of complex constituents by stay green proteins [153, 154]. The gene that encodes the protein STAY GREEN (SP803280_c105792_g2) was more expressed in the T compared to the $\mathrm{M}$ segment, suggesting a possible beginning of senescence mechanism.

Other pigments, such as carotenoids, are also degraded during leaf senescence. The gene encoding the enzyme carotenoid 9,10(9,10')-cleavage dioxygenase (SP803280_c114734_g1) responsible for the cleavage of carotenoids [155] was also upregulated in the T segment. These results indicate that the leaf senescence process begins at the leaf tip and that chlorophyll and carotenoids degradation are associated [136]. Although our analysis did not indicate chlorophyll degradation (Fig. 3), it seems that the leaf tip, at the molecular level, presents indications of the onset of senescence.

The GO enrichment analysis also revealed GO terms associated with "aging" and "cell killing" overrepresented at the T segment (Table S9 - Additional file 10). Three 1-aminocyclopropane-1-carboxylate oxidase are on this list, responsible for an important step on ethylene production [156]. Ethylene is a gaseous phytohormone and has an important role on the onset and progression of senescence [157]. The inhibition of its perception or biosynthesis in tobacco and tomato caused delayed onset of leaf senescence and lower expression of SAGs, which was also found in Arabidopsis ethylene-insensitive mutants [158-161].

\section{Gene expression peaking at the middle section of the leaf} Besides describing the physiological and transcriptional variation in sugarcane leaves, we also aimed to identify genes associated with high photosynthetic activity. To achieve this goal, we evaluated, amongst all genes expressed on our transcriptome, those that peaked their expression at the $M$ segment, region with the highest photosynthetic capacity (Fig. 2 and Figures S4 and S5 Additional file 1). For that, we utilized the software TimeSearcher [162] using the Z-values based on FPKM (Figure S13 - Additional file 1). We then looked for genes that had a normalized expression value ( $Z$-value) at the $\mathrm{B} 0, \mathrm{~B}$ and $\mathrm{T}$ segments lower than the average normalized expression for the $\mathrm{M}$ segment $(Z$-value $<0)$. In such a way, we identified 986 genes with expression values higher at the $\mathrm{M}$ segment and $26 \%$ of which having functional annotation (Table S18 - Additional file 13).

GO enrichment analysis indicated that some pathways were enriched in the M segment (Table S19 - Additional file 13), even though the number of genes on each pathway is small. Some of them are related to starch and sucrose metabolism (SP803280_c92108_g1; SP803280_c109193_g3;
SP803280_c102083_g2; SP803280_c90189_g1), amino sugar and nucleotide sugar metabolism (SP803280 c102083_g2; SP803280_c90189_g1; SP803280_c110680_g1; SP803280_c106685_g3); N metabolism (SP803280_c45 945_g1; SP803280_c93257_g1) and plant hormone signal transduction (SP803280_c82109_g1; SP803280_c99047_g1).

From the genes directly related to photosynthesis, only two RubisCO transcripts (SP803280_c90358_g1 and SP803280_c102172_g2) presented higher expression at the $\mathrm{M}$ segment. However, our in vivo (Figure S5A Additional file 1) and in vitro activities (Fig. 2b), and immunoblotting analysis (Fig. 2b) indicated no differences between segments (except B0 that always had the lowest values). Intriguingly, none PEPcase transcript was identified in this analysis, contrasting with the physiological and biochemical assays (Fig. 2a and Figure S5A- Additional file 1). As mentioned before, PEPcase gene is known to suffer both post-transcriptional and posttranslational modifications [98, 101, 102], which could justify such inconsistence between gene expression and protein activity and amount.

An aquaporin belonging to SIP1 family (SP803280 c107872_g1) and the Myb-related protein Zm38 (SP803280_c114598_g1) were also identified. The silencing of the aquaporin homolog in Arabidopsis has shown to decrease osmotic water permeability in mesophyll and bundle sheath cells, mesophyll $\mathrm{CO}_{2}$ conductance, photosynthesis, transpiration, and shoot biomass in Arabidopsis [163]. This indicates that aquaporins can contribute to the establishment of high photosynthetic rates on the middle of the leaf blade. MYB transcription factors are related to leaf development in tobacco [128] and to leaf and shoot architecture in tomato [129]. In addition, the myb-related protein $\mathrm{Zm} 38$ regulates negatively genes involved in anthocyanin biosynthesis [164] and also epidermal cell development $[165,166]$.

A protein that has strong similarity to the C-terminal region of the Mid domain of the Argonaute (AGO) protein MEL1 (SP803280_c113083_g2) was also present at the M. MEL1 is associated with small RNA-directed regulatory pathways [167] and some studies have already indicated the importance of small RNAs on abiotic stress response [168-170]. Even though it is not clear how many AGO genes there are in sugarcane genome, we were able to identify all the Rice AGO genes in four groups of orthologues (LeafDev_mcl15_5, LeafDev_mcl15_83, LeafDev mcl15_342 and LeafDev_mcl15_6159; Additional file 6) and in each of them there is at least one sugarcane representative. However, the protein SP803280_c113083_g2 is not present in any of these groups of orthologous genes and may represent a novelty in sugarcane.

Developmental studies indicate the importance of AGO on rice sporogenesis [171], Arabidopsis female gamete formation [172], leaf, shoot and apical meristem 
development [173-175], stomata development [176], control of meiosis and DNA repair [177] and shoot meristem initiation in rice [178]. In Arabidopsis, the role of small RNAs on leaf development is well studied [179] and there is also evidence of the importance of miRNA in on leaf development of other species such as celery [180] and potato [181]. Although there is no direct evidence, our study in sugarcane and the work from Li et al. [44] in maize suggest that miRNAs must play an important role on leaf development of grasses, but it is still a topic to be explored.

\section{Conclusions}

This is the first report evaluating sugarcane leaf segments representing different developmental stages and it has proven to be a valuable tool for investigating the genes that might be regulators of $\mathrm{C}_{4}$ syndrome. In our study we describe detailed physiological and biochemical analyses among leaf segments. We also have made use of the next generation sequencing technology RNA-seq to identify molecular differences along the leaf blade of sugarcane. In addition, we compared our data with previous work recently published for maize [48]. This analysis revealed that leaf development differs significantly between sugarcane and maize based on their transcriptional profile. Although this comparison was limited in some aspects, it indicates large differences between these two species pointed out the importance of studying other crops in order to acquire substantial novel knowledge to enable improvement of the photosynthetic capacity followed by increase in productivity.

\section{Methods}

\section{Plant material and growth conditions}

Sugarcane stalks from genotype SP80-3280 (Saccharum spp.) were kindly provided by Centro de Tecnologia Canavieira (CTC), Piracicaba SP, Brazil. Stalks were sectioned in order to have only one bud per section and germinated in trays containing vermiculite. After one month, plants with the same height were transferred to pots $(3.5 \mathrm{~L})$ containing pine-bark substrate and vermiculite (1:1). Plants were fertilized with N:P:K (10:10:10) every 15 days. The pots were watered daily and every week their distribution inside the greenhouse was randomized. After 60 days, leaf segments were collected between 10:00 $\mathrm{h}$ and 14:00 h. The first $2 \mathrm{~cm}$ of the base of the first leaf with exposed dewlap (leaf +1 following the system by van Dillewijn [182]) were collected. For the other segments, each leaf was measured and was divided into three equal thirds. Samples were taken considering $1 \mathrm{~cm}$ of each side of the middle of each third, except for the tip, according to Figure S3 - Additional file 1. The segments were named Base "zero" (B0); Base (B); Middle (M) and Tip (T). Samples were frozen in liquid nitrogen, ground to a fine powder and stored at $-80{ }^{\circ} \mathrm{C}$ until further processing. Additionally, in order to improve the gene space coverage of the de novo transcriptome assembly we included a sample resulting from pooling different developmental stages and tissues from an additional plant of the same genotype, and the collected tissues were: leaf +1 , shoot, and root; each after one and two months of growth under the same conditions described above.

\section{PEPcase and RubisCO activity and quantification}

For determining the catalytic activity of the enzymes, aliquots of $50 \mathrm{mg}$ FW were extracted by vigorous shaking with extraction buffer containing $10 \%(\mathrm{v} / \mathrm{v})$ glycerol, $0.25 \%(\mathrm{w} / \mathrm{v})$ BSA, $0.1 \%(\mathrm{v} / \mathrm{v})$ Triton X-100, $50 \mathrm{mM}$ Hepes/KOH, pH 7.5, $10 \mathrm{mM} \mathrm{MgCl}$, 1 mM EDTA, $1 \mathrm{mM}$ EGTA, $1 \mathrm{mM}$ benzamidine, $1 \mathrm{mM} \varepsilon$-aminocapronic acid, $1 \mathrm{mM}$ phenylmethylsulfonyl fluoride, $10 \mathrm{mM}$ leupeptin, and $1 \mathrm{mM}$ DTT [183]. PEPcase was measured spectrophotometrically at $340 \mathrm{~nm}$ by coupling the reduction of oxaloacetate by $\mathrm{NADH}$ in the presence of malate dehydrogenase $(\mathrm{MDH})$ [184]. The reaction mixture contained enzyme extract, $25 \mathrm{mM}$ Tris- $\mathrm{HCl}, \mathrm{pH} 8,5 \mathrm{mM} \mathrm{MgCl}$, $4 \mathrm{mM}$ DTT, $5 \mathrm{mM} \mathrm{NaHCO}$, $5 \mathrm{mM}$ glucose-6-phosphate, $5 \mathrm{mM}$ PEP, $0.2 \mathrm{mM}$ NADH and $2 \mathrm{U}$ MDH. RubisCO activity was assayed by coupling RuBP carboxylation to NADH oxidation [185]. The reaction mixture contained enzyme extract, $100 \mathrm{mM}$ bicine $/ \mathrm{NaOH} \mathrm{pH} 8,20 \mathrm{mM}$ $\mathrm{MgCl}_{2}, 25 \mathrm{mM} \mathrm{NaHCO}_{3}, 5 \mathrm{mM}$ phosphocreatine, $3.5 \mathrm{mM}$ ATP, $0.25 \mathrm{mM} \mathrm{NADH}, 4.8 \mathrm{U}$ G3PDH, $4.8 \mathrm{U}$ creatine phosphofructokinase, $4.8 \mathrm{U}$ G3P kinase and $0.5 \mathrm{mM}$ $\mathrm{RuBP}$. For initial activity, the assay was performed directly after protein extraction. For total activity, leaf extracts were incubated in the assay mix without RuBP for $5 \mathrm{~min}$ to fully carbamylate RubisCO [186].

The abundances of PEPcase and RubisCO were estimated by Western Blot [187].

\section{Total nitrogen, carbon, carbon isotope discrimination and chlorophyll quantification}

Powdered dried leaves ( 3 to $4 \mathrm{mg}$ ) were encapsulated in tin capsules and total $\mathrm{N}$, total $\mathrm{C}$ and carbon isotope discrimination were evaluated at the UC Davis Stable Isotope Facility. Carbon isotope discrimination was calculated as $\Delta^{13} \mathrm{C}$ according to Farquhar [188]. Chlorophyll was quantified in ethanolic extracts of each leaf segment according to Cross et al. [189].

\section{Carbohydrates}

Soluble sugars were extracted three times with $80 \%(\mathrm{v} / \mathrm{v})$ ethanol at $80^{\circ} \mathrm{C}$ for $20 \mathrm{~min}$. The supernatants were pooled, dried using a centrifugal vacuum concentrator, resuspended in pure water and filtered. Sugars were separated by high 
performance anion exchange chromatography with pulsed amperometric detection (HPAEC-PAD, ICS 3000, Thermo Scientific Dionex) on a CarboPac PA-1 $4 \times 250 \mathrm{~mm}$ column set (Thermo Scientific Dionex) using a gradient of eluent A (water) and eluent $\mathrm{B}(200 \mathrm{mM} \mathrm{NaOH})$, and a flow rate $0.8 \mathrm{~mL} \mathrm{~min}^{-1}$ during $22 \mathrm{~min}$ as follows: $0-12 \mathrm{~min}, 50 \% \mathrm{~B} /$ $50 \%$ A; $12.1-17 \mathrm{~min}, 100 \% \mathrm{~B}$; and $17.1-22 \mathrm{~min}, 50 \% \mathrm{~B} /$ $50 \%$ A. Myo-inositol, glucose, sucrose and fructose were identified and quantified by comparison with original standards using Chromeleon software (version 6.8, Thermo Scientific Dionex).

\section{Statistical analysis}

All the physiological and biochemical data was subjected analyses of variance (ANOVA) and mean values were compared by the Tukey test $(\mathrm{p}<0.05)$ using the software Origin (OriginLab, USA).

\section{RNA-Seq \\ RNA extraction, library construction, sequencing and qRT-PCR validation}

Total RNA of four independent replicates for each sample was extracted using Trizol (Invitrogen, USA) according to manufacturer's instructions with an additional sodium acetate/ethanol precipitation step. RNA quality and concentration was assessed by gel electrophoresis, NanoDrop (Thermo Fisher Scientific) and Bioanalyzer (Agilent Technologies). Only RNA samples with a minimum RNA Integrity Number (RIN) of 7 were further processed. Libraries were produced using TruSeq Stranded mRNA Sample Prep Kit (Illumina), which enriches the sample for mRNAs (poly-A containing transcripts) and maintains the information about the strand that was transcribed, according to the manufacturer's instructions. Clusters were made on c-Bot (Illumina) and paired-end sequencing was carried out on a Hi-Seq 2500 (Illumina) using TruSeq SBS Kit v3 - HS (Illumina). Samples from plants 234, 138 and 163 and DP3 (pool) were sequenced in the LACTAD Facility (University of Campinas, Campinas, Brazil) and samples from an additional biological replicate (plant 235) were sequenced in our institute (CTBE, Campinas, Brazil).

To validate the RNA-seq results, RNA from two additional independent biological replicates were extracted using Trizol (Invitrogen, USA) as mentioned above, and then treated with DNase I Amplification Grade (Invitrogen, USA). cDNA was produced with SuperScript ${ }^{\circ}$ III (Invitrogen). qRT-PCR was conducted using Sybr Green Master Mix (Applied Biosystems) on an ABI 7500 (Applied Biosystems) real-time PCR system. Primers for 14 selected genes (Table S20 - Additional file 14) were designed using Primer Express 2.0 software and the efficiency of each pair tested using LinRegPCR software [190].

\section{Transcript assembly and annotation} Short read pre-processing and de novo transcript assembly Short-reads were pre-processed using Trimmomatic v0.32 in order to remove remaining adaptor sequences and to carry out quality trimming, using a sliding window of size $1 \mathrm{bp}$ and a minimum Q value of 20 [191]. In a first iteration, clean reads were de novo assembled with Trinity (version r20140413p1) [192, 193], except for reads coming from plant 235, which had not been sequenced at this stage. Possible contaminants were identified using MEGAN5 (http://ab.inf.uni-tuebingen.de/ software/megan5/). In a second iteration, reads were mapped against the genomes of representative contaminants, also against mitochondrial (GenBank ACC: NC_008360.1) and plastid (GenBank ACC: NC_005878.2) sequences, and unmapped reads were re-assembled using Trinity. Elimination of contaminating sequences was assessed with MEGAN5 and contigs assigned to Viridiplantae were retained for further analyses, as well as those that did not have any hits against the NCBI nucleotide database, because we can not exclude that these originate from sugarcane.

The quality and completeness of the transcript assembly was evaluated using Transrate [194] by comparing it to the transcripts and proteins in the Sorghum bicolor genome [195], and with CEGMA [196], which identifies a set of 248 highly conserved, usually single-copy, eukaryotic genes.

\section{Transcriptome annotation}

Transcript contigs likely originating from sugarcane were annotated with the Trinotate pipeline (http://trino tate.sourceforge.net/), which includes sequence similarity searches against the UniProt and UniRef databases, prediction of signal peptides using SignalP [197], prediction of transmembrane regions using THMM [198] and identification of ribosomal genes with RNAmmer [199]. The KEGG Automatic Annotation Server was used to assign transcripts into KEGG orthologous groups and in house perl scripts were used to retrieve the associated metabolic pathways using KEGG web services [200]. OrthoMCL was employed to identify groups of orthologous genes among sugarcane, Sorghum bicolor, Zea mays, Setaria italica, Oryza sativa, and Arabidopsis thaliana, using an inflation value of 1.5. The full set of proteins of these species was downloaded from Phytozome [201]. Genes encoding transcription factors and other transcriptional regulators were identified following the approach described in Perez-Rodriguez et al. [66].

\section{Transcript abundance estimation and differential expression analyses}

During the de novo assembly by Trinity, the software partitions the input data into many individual de Bruijn graphs, 
each one representing a single "putative" locus or gene, and then process to split the alternatively spliced forms of that gene [193]. The estimation of transcript abundances was carried out with eXpress [202], summarizing the read counts at the level of gene as defined by Trinity. Differential expression analyses for the leaf +1 developmental stages were carried out with edgeR, controlling for individual/ plant variation, i.e., a paired statistical design [203]. Gene counts per sample were normalized using the Trimmed Mean of M-values method - TMM -[204] as implemented in edgeR, in order to account for inter-sample RNA population variation. Only transcripts that achieved 1 count per million, after TMM normalization, in at least three samples were considered as expressed and thus retained for further analysis. Multiple testing was controlled allowing a False Discovery Rate (FDR) of 0.05. Comparisons between segments were performed subtracting distal from basal segments originating the three orthogonal contrasts: Base "zero" vs. Base (B0-B); Middle vs. Base (M-B); Tip vs. Middle (T-M). R code used for differential gene expression analyses is available as Additional file 8.

\section{Comparison of transcript profiles of orthologous genes between sugarcane and maize along the leaf developmental gradient}

We used the expression data (read counts) reported in Wang et al. [48], and processed it in the same way as our sugarcane data (see above). Transcription expression values were reported as FPKM, and in the case of sugarcane we reported the averaged, among replicates, FPKM. We used the list of 30,530 maize and rice orthologous genes from Wang et al. [48] and extracted their orthologous genes in sugarcane for the cases where the orthology relationship was still 1:1 between maize and sugarcane. Finally, the Spearman correlation coefficient between each sugarcane leaf +1 segment and each maize leaf segment was calculated.

\section{Availability of supporting data}

The data sets supporting the results of this article are available in the NCBI's Short Read Archive (SRA) under the accession numbers: SRR1979656 to SRR1979669 and SRR1974519; the assembled transcriptome is available at NCBI's Transcriptome Shotgun Assembly (TSA) under accession number: GCZX00000000 and datasets are also available at http://bce.bioetanol.cnpem.br/ sugarcanetranscriptome.

\section{Additional files}

Additional file 1: It is comprised by 13 Additional figures and methodologies that complement the data presented in the manuscript. Figure S1. Distribution of leaf length. Figure S2. Phenotype of 60 days-old plants. Figure S3. Planning for sample collection.
Additional Methodology of leaf gas exchange and photochemistry evaluation on the B and M segments: on this supplemental topic we described the methodology used to produce Additional Fig. 4 and 5. Figure S4. Light response curves for different leaf segments. Figure S5. Responses of leaf $\mathrm{CO}_{2}$ assimilation to increasing intercellular $\mathrm{CO}_{2}$ concentration $\left(C_{i}\right)$ for different leaf segments. Figure S6. Stomata counting in $2 \mathrm{~cm}$ segments of sugarcane leaf. Figure S7. Venn Diagram representing groups of orthologous genes shared between the five species (Sorghum bicolor, Setaria italica, Saccharum sp. SP80-3280, Oryza sativa and Zea mays). Figure S8. Protein content of sugarcane leaf segments. Figure S9. Expression patterns exhibited by the 14 genes identified in all contrasts (Figure 5 on the manuscript). Figure S10. Water content. Figure S11. Phylogenetic tree of the Trehalose 6-Phosphate Synthase family. Figure S12. Expression pattern of cell wall related genes. Figure S13. Expression pattern of genes peaking at segment M. Additional References. References of the Methodology of Gas exchange and fluorescence evaluation. (DOCX $6742 \mathrm{~kb}$ )

Additional file 2: Fasta file with the assembly. Transcript assembly as obtained by trinity and submitted to the TSA at NCBI. (BZ2 $57956 \mathrm{~kb}$ )

Additional file 3: Assembled transcripts were annotated with Trinotate (https://trinotate.github.io/). Transcripts were mapped against the databases UniProt, PFAM, UniRef90. Subcellular location was predicted using SignalP. Transmembrane regions were identify by tmHMM. Ribosomal RNA genes were predicted by RNAMMER. All results were loaded into a SQLite DB as per Trinotate instruction and results were exported into tabular format. For details of the format of this table please check https://trinotate.github.io/. (BZ2 $9438 \mathrm{~kb}$ )

Additional file 4: Sugarcane Trinity contigs were mapped to KEGG pathway using the single-directional best hit approach available in the KEGG Automatic Annotation Service (http://www.genome.jp/ tools/kaas/). This is a table with the results of such mapping. The table has three columns, 1. The name of the sugarcane transcript/contig, 2. The identifier for the KEGG pathway, and 3. The name of the pathway. (BZ2 $76 \mathrm{~kb}$ )

Additional file 5: Transcription associated proteins were identified following the approached presented in Perez-Rodrigues et al 2010. The table has 5 fields. 1. Gene identifier, as defined in the text, 2 . Transcript identifier, 3. Protein identifier, 4. TAP family, 5. This filed has always the value TAP. (BZ2 $30 \mathrm{~kb}$ )

Additional file 6: Table with the list of orthologous genes between the five species: Sorghum bicolor (Abbreviation: SBIC), Setaria italica (Abbreviation: SITA), Saccharum sp. SP80-3280 (Abbreviation: SACC), Oryza sativa (Abbreviation: OSAT) and Zea mays (Abbreviation: ZMAY). Groups of orthologous genes were identified by OrthoMCL with an inflation value of 1.5. (BZ2 $1258 \mathrm{~kb})$

Additional file 7: This Additional File is an Excel File containing 3 spreadsheets (Additional Tables 1-3) with the results of our differential expression analysis contrasting two leaf segments. Table S1. Differentially expressed genes between the contrast B-BO. Table S2. Differentially expressed genes between the contrast M-B. Table S3. Differentially expressed genes between the contrast T-M. (XLSX $150 \mathrm{~kb}$ )

Additional file 8: Input data (read count per gene per condition) and $R$ code, to reproduce the differential gene expression analysis for the sugarcane leaf development segments. (BZ2 $15159 \mathrm{~kb}$ )

Additional file 9: Input data and R code to produce the heatmap shown in HeatMapMaize_vs_Sugarcane. For the comparison, all the orthologous genes used in Wang et al. (2014) that were identified as one to one orthologues between Sugarcane and Maize by OrthoMCL were used. (BZ2 $1620 \mathrm{~kb}$ )

Additional file 10: This Additional File is an Excel File containing 6 spreadsheets (Additional Tables 4-9) with the results of our gene ontology analysis for each leaf segment. Table S4. Enriched gene ontology terms for genes over-expressed at BO identified on the contrast B-BO. Table S5. Enriched gene ontology terms for genes over-expressed at B identified on the contrast B-BO. Table S6. Enriched gene ontology 
terms for genes over-expressed at B identified on the contrast M-B. Table S7. Enriched gene ontology terms for genes over-expressed at $M$ identified on the contrast M-B. Table S8. Enriched gene ontology terms for genes over-expressed at M identified on the contrast T-M. Table $\mathbf{5 9 .}$ Enriched gene ontology terms for genes over-expressed at T identified on the contrast T-M. (XLSX $39 \mathrm{~kb}$ )

Additional File 11: This Additional File is an Excel File containing 2 spreadsheets (Additional Tables 10 and 11) showing the identification of genes related to cell wall modification and gene putatively related to suberin biosynthesis. Table S10. Cell Wall related genes identified in each contrast. Table S11. Genes putatively involved in suberin biosynthesis identified in each contrast. (XLSX $23 \mathrm{~kb}$ )

Additional file 12: This Additional File is an Excel File containing 6 spreadsheets (Additional Tables 12-17) with the results of our transcriptional factors families enrichment analysis for each leaf segment. Table S12. Transcriptional factors families enriched on BO considering the contrast B-BO. In red are highlighted the families with significative enrichment. Table S13. Transcriptional factors families enriched on B considering the contrast B-BO. In red are highlighted the families with significative enrichment. Table S14. Transcriptional factors families enriched on B considering the contrast M-B. Table S15.

Transcriptional factors families enriched on $\mathrm{M}$ considering the contrast

M-B. Table S16. Transcriptional factors families enriched on M

considering the contrast

T-M. Table S17. Transcriptional factors families enriched on T considering the contrast T-M. In red are highlighted the families with significative enrichment. (XLSX $32 \mathrm{~kb}$ )

Additional file 13: This Additional File is an Excel File containing 2 spreadsheets (Additional Tables 18 and 19) indicating the genes identified as having their peak expression at the middle segment and demonstrating the gene ontology analysis of those genes. Table S18. Genes with expression peaking at the M segment. Table S19. Enriched KEGG pathways for genes with expression peaking at the M segment. In grey are highlighted the significant KEGG pathways. (XLSX $92 \mathrm{~kb}$ )

Additional file 14: List of sugarcane genes and primers used for qRT-PCR. Table S20. qRT-PCR Primers. (XLSX $9 \mathrm{~kb}$ )

\section{Abbreviations}

A: Photosynthesis; B0: Base "zero" segment; B: Base segment; $C_{3}$ : 3-carbon compound; $\mathrm{C}_{4}$ : 4-carbon compound; DE: Differentially expressed; ETR: Electron transport rate; FPKM: Fragments per kilobase of exon per million fragments mapped; GO: Gene ontology; K: Potassium; k: PEPcase: carboxylation efficiency; KEGG: Kyoto encyclopedia of genes and genomes; LogFC: Log Fold Change; M: Middle segment; N: Nitrogen; P: Phosphorus; PEPcase: Phosphoenolpyruvate carboxylase; PEPCK: Phosphoenolpyruvate carboxykinase: PEP: Phosphoenolpyruvate: PNUE: Photosynthetic nitrogenuse efficiency; PSII: Photosystem II; qRT-PCR: Quantitative Real Time PCR; RubisCO: Ribulose-1,5-bisphosphate carboxylase/oxygenase; RuBP: Ribulose1,5-bisphosphate; T: Tip segment; $V_{\text {max }}$ : Rubis $C O$ capacity; $\Delta^{13} \mathrm{C}$ : Carbon isotopic discrimination.

\section{Competing interests}

The authors declare that they have no competing interests.

\section{Authors' contributions}

L.M. is the lead investigator and conceived the study. R.V.R., P.E.R.M., D.B., L.P.C. and M.C.M.M. contributed to the execution and interpretation of physiological data. D.M.R.P. carried out the transcriptome analyses, assembly annotations and detection of differentially expressed genes. L.M., M.C.M.M. R.V.R., P.E.R.M., D.B., L.P.C., D.M.R.P., M.T.V.L., C.A.L. and M.M. contributed in the interpretation and discussion of results. L.M. M.C.M.M and D.M.R.P. wrote the manuscript. All authors have read and approved the final version of the manuscript.

\section{Acknowledgements}

We thank Lucia Daniela Wolf for excellent technical support in HPAEC-PAD analysis. We thank Cristina Rodrigues $\mathrm{G}$. Sales for the support during RubisCO and PEPcase activity assays. We thank Tom Brutnell's group for kindly providing the read counts and gene lengths used in the analysis of leaf development in maize. RVR is a research fellow of the National Council for Scientific and Technological

Development (CNPq, Brazil). This work was supported by FAPESP as a Regular Research Grant (2012/23345-0)

\section{Author details}

'Laboratório Nacional de Ciência e Tecnologia do Bioetanol (CTBE), Centro Nacional de Pesquisa em Energia e Materiais (CNPEM), Caixa Postal 6192 13083-970 Campinas, SP, Brazil. 'Laboratório de Fisiologia de Plantas "Coaracy M. Franco", Centro de Pesquisa e Desenvolvimento em Ecofisiologia e Biofísica, Instituto Agronômico, Caixa Postal 28, Campinas 13020-902SP, Brazil. ${ }^{3}$ Departamento de Biologia de Plantas, Universidade Estadual de Campinas, Caixa Postal 6109, Campinas 13083-970SP, Brazil. " Laboratório Max Feffer de Genética de Plantas, Departamento de Genética, Universidade de São Paulo, Caixa Postal 83, Piracicaba 13400-970SP, Brazil. ${ }^{5}$ Laboratório de Genoma Funcional, Instituto de Biologia, Universidade Estadual de Campinas Campinas, Caixa Postal 6109, Campinas 13083-862SP, Brazil.

Received: 21 September 2015 Accepted: 17 December 2015

Published online: 29 December 2015

\section{References}

1. Tammisola J. Towards much more efficient biofuel crops - can sugarcane pave the way? GM Crops. 2010;1(4):181-98.

2. Moore P. Temporal and spatial regulation of sucrose accumulation in sugarcane stem. Aust J Plant Physiol. 1995;22(4):69-80.

3. Waclawovsky AJ, Sato PM, Lembke CG, Moore PH, Souza GM. Sugarcane for bioenergy production: an assessment of yield and regulation of sucrose content. Plant Biotechnol J. 2010;8(3):263-76.

4. D'Hont A. Unraveling the genome structure of polyploids using FISH and GISH; examples of sugarcane and banana. Cytogenet Genome Res. 2005:109(1-3):27-33.

5. D'Hont A, Grivet L, Feldmann P, Rao S, Berding N, Glaszmann JC. Characterisation of the double genome structure of modern sugarcane cultivars (Saccharum spp.) by molecular cytogenetics. Mol Gen Genet. 1996:250(4):405-13.

6. D'Hont A, Lu YH, León DG, Grivet L, Feldmann P, Lanaud C, et al. A molecular approach to unraveling the genetics of sugarcane, a complex polyploid of the Andropogoneae tribe. Genome. 1994;37(2):222-30.

7. Aitken KS, McNeil MD, Berkman PJ, Hermann S, Kilian A, Bundock PC, et al. Comparative mapping in the Poaceae family reveals translocations in the complex polyploid genome of sugarcane. BMC Plant Biol. 2014;14:190.

8. Grivet L, Arruda P. Sugarcane genomics: depicting the complex genome of an important tropical crop. Curr Opin Plant Biol. 2002;5(2):122-7.

9. Joyce $\mathrm{P}$, Hermann S, O'Connell A, Dinh $\mathrm{Q}$, Shumbe L, Lakshmanan P. Field performance of transgenic sugarcane produced using Agrobacterium and biolistics methods. Plant Biotech J. 2014:12(4):411-24.

10. Manickavasagam M, Ganapathi A, Anbazhagan VR, Sudhakar B, Selvaraj N, Vasudevan $\mathrm{A}$, et al. Agrobacterium-mediated genetic transformation and development of herbicide-resistant sugarcane (Saccharum species hybrids) using axillary buds. Plant Cell Rep. 2004;23(3):134-43.

11. Gao SJ, Damaj MB, Park JW, Beyene G, Buenrostro-Nava MT, Molina J, et al. Enhanced transgene expression in sugarcane by co-expression of virusencoded rna silencing suppressors. Plos One. 2013;8(6):13.

12. Molinari HBC, Marur CJ, Daros E, de Campos MKF, de Carvalho J, Bespalhok $\mathrm{JC}$, et al. Evaluation of the stress-inducible production of proline in transgenic sugarcane (Saccharum spp.): osmotic adjustment, chlorophyll fluorescence and oxidative stress. Physiol Plant. 2007;130(2):218-29.

13. Zale J, Jung, J.H., Kim, J.Y., Pathak, B., Karan, R.Liu, H.Chen, X.Wu, H. Candreva, J.Zhai Z.Shanklin, J. Altpeter, F.: Metabolic engineering of sugarcane to accumulate energy-dense triacylglycerols in vegetative biomass. Plant Biotech J. 2015; doi: 10.1111/pbi.12411.

14. Menossi M, Silva-Filho MC, Vincentz M, Van-Sluys MA, Souza GM. Sugarcane functional genomics: gene discovery for agronomic trait development. Int J Plant Genomics. 2008;2008:458732.

15. Arruda P. Genetically modified sugarcane for bioenergy generation. Curr Opin Biotechnol. 2012;23(3):315-22.

16. Marchiori P, Machado E, Ribeiro V Photosynthetic limitations imposed by selfshading in field-grown sugarcane varieties. Field Crops Res. 2014;155:30-7. 
17. Makino A. Photosynthesis, grain yield, and nitrogen utilization in rice and wheat. Plant Physiol. 2011;155(1):125-9.

18. Long SP, Zhu XG, Naidu SL, Ort DR. Can improvement in photosynthesis increase crop yields? Plant Cell Environ. 2006;29(3):315-30.

19. De Souza AP, Gaspar M, Da Silva EA, Ulian EC, Waclawovsky AJ, Nishiyama $\mathrm{MY}$, et al. Elevated $\mathrm{CO}_{2}$ increases photosynthesis, biomass and productivity, and modifies gene expression in sugarcane. Plant Cell Environ. 2008;31(8):1116-27.

20. Marchiori PER, Ribeiro RV, da Silva L, Machado RS, Machado EC, Scarpari MS. Plant growth, canopy photosynthesis and light availability in three sugarcane varieties. Sugar Tech. 2010;12(2):160-6.

21. Manandhar-Shrestha K, Tamot B, Pratt EP, Saitie S, Bräutigam A, Weber AP, et al. Comparative proteomics of chloroplasts envelopes from bundle sheath and mesophyll chloroplasts reveals novel membrane proteins with a possible role in c4-related metabolite fluxes and development. Front Plant Sci. 2013;4:65

22. Langdale JA. $\mathrm{C}_{4}$ cycles: past, present, and future research on C4 photosynthesis. Plant Cell. 2011;23(11):3879-92.

23. Bräutigam A, Mullick T, Schliesky S, Weber AP. Critical assessment of assembly strategies for non-model species mRNA-Seq data and application of next-generation sequencing to the comparison of $C_{3}$ and $C_{4}$ species. J Exp Bot. 2011;62(9):3093-102.

24. Denton AK, Simon R, Weber AP. $C_{4}$ photosynthesis: from evolutionary analyses to strategies for synthetic reconstruction of the trait. Curr Opin Plant Biol. 2013;16(3):315-21.

25. Wardlaw I. The control of carbon partitioning in plants. New Phytol. 1990;116(3):341-81.

26. Paul MJ, Foyer $\mathrm{CH}$. Sink regulation of photosynthesis. J Exp Bot. 2001;52(360):1383-400.

27. McCormick AJ, Watt DA, Cramer MD. Supply and demand: sink regulation of sugar accumulation in sugarcane. J Exp Bot. 2009;60(2):357-64.

28. McCormick AJ, Cramer MD, Watt DA. Sink strength regulates photosynthesis in sugarcane. New Phytol. 2006;171(4):759-70.

29. Lobo AKM, Martins MD, Neto MCL, Machado EC, Ribeiro RV, Silveira JAG. Exogenous sucrose supply changes sugar metabolism and reduces photosynthesis of sugarcane through the down-regulation of Rubisco abundance and activity. J Plant Physiol. 2015;179:113-21.

30. Sheen J. Metabolic repression of transcription in higher plants. Plant Cell. 1990;2(10):1027-38.

31. Black C, Loboda T, Chen J, Sung S. Can sucrose cleavage enzymes serve as markers for sink strength and is sucrose a signal molecule during plant sink development? in International Symposium on Sucrose Metabolism. Amer Soc Plant Physiol. 1995;49-64

32. Koch KE, Wu Y, Xu J. Sugar and metabolic regulation of genes for sucrose metabolism: potential influence of maize sucrose synthase and soluble invertase responses on carbon partitioning and sugar sensing. J Exp Bot. 1996:47 Spec No:1179-85.

33. Koch KE. Carbohydrate-modulated gene expression in plants. Annu Rev Plant Physiol Plant Mol Biol. 1996;47:509-40.

34. Pego JV, Kortstee AJ, Huijser C, Smeekens SC. Photosynthesis, sugars and the regulation of gene expression. J Exp Bot. 2000;51 Spec No:407-16.

35. Rolland F, Moore B, Sheen J. Sugar sensing and signaling in plants. Plant Cell. 2002;14(Suppl):S185-205.

36. Lima D, Santos $H$, Tiné $M$, Molle F, Buckeridge M. Patterns of expression of cell wall related genes in sugar cane. Genetics Mol Biol. 2001;24(1-4):191-8.

37. Carson D, Huckett B, Botha F. Sugarcane ESTs differentially expressed in immature and maturing internodal tissue. Plant Sci. 2002;162:289-300.

38. Casu RE, Jarmey JM, Bonnett GD, Manners JM. Identification of transcripts associated with cell wall metabolism and development in the stem of sugarcane by Affymetrix GeneChip Sugarcane Genome Array expression profiling. Funct Integr Genomics. 2007;7(2):153-67.

39. Casu RE, Dimmock CM, Chapman SC, Grof CP, Mclntyre CL, Bonnett GD, et al. Identification of differentially expressed transcripts from maturing stem of sugarcane by in silico analysis of stem expressed sequence tags and gene expression profiling. Plant Mol Biol. 2004;54(4):503-17.

40. Casu RE, Grof CP, Rae AL, Mclntyre CL, Dimmock CM, Manners JM. Identification of a novel sugar transporter homologue strongly expressed in maturing stem vascular tissues of sugarcane by expressed sequence tag and microarray analysis. Plant Mol Biol. 2003;52(2):371-86.
41. Zambrosi FCB, Ribeiro RV, Marchiori PER, Cantarella H, Landell MGA. Sugarcane performance under phosphorus deficiency: physiologica responses and genotypic variation. Plant Soil. 2015;386(1-2):273-83.

42. Ribeiro RV, Machado RS, Machado EC, Machado D, Magalhaes JR, Landell MGA. Revealing drought-resistance and productive patterns in sugarcane genotypes by evaluating both physiological responses and stalk yield. Exp Agricul. 2013;49(2):212-24.

43. Cahoon AB, Takacs EM, Sharpe RM, Stern DB. Nuclear, chloroplast, and mitochondrial transcript abundance along a maize leaf developmental gradient. Plant Mol Biol. 2008;66(1-2):33-46.

44. Li P, Ponnala L, Gandotra N, Wang L, Si Y, Tausta SL, et al. The developmental dynamics of the maize leaf transcriptome. Nat Genet. 2010;42(12):1060-7.

45. Majeran W, Friso G, Ponnala L, Connolly B, Huang M, Reidel E, et al. Structural and metabolic transitions of C4 leaf development and differentiation defined by microscopy and quantitative proteomics in maize. Plant Cell. 2010;22(11):3509-42.

46. Sharpe RM, Mahajan A, Takacs EM, Stern DB, Cahoon AB. Developmental and cell type characterization of bundle sheath and mesophyll chloroplast transcript abundance in maize. Curr Genet. 2011;57(2):89-102.

47. Chang YM, Liu WY, Shih AC, Shen MN, Lu CH, Lu MY, et al. Characterizing regulatory and functional differentiation between maize mesophyll and bundle sheath cells by transcriptomic analysis. Plant Physiol. 2012;160(1):165-77.

48. Wang L, Czedik-Eysenberg A, Mertz R, Si Y, Tohge T, Nunes-Nesi A, et al. Comparative analyses of $C_{4}$ and $C_{3}$ photosynthesis in developing leaves of maize and rice. Nat Biotech. 2014;32:1158-65.

49. Pick TR, Bräutigam A, Schlüter U, Denton AK, Colmsee C, Scholz U, et al. Systems analysis of a maize leaf developmental gradient redefines the current C4 model and provides candidates for regulation. Plant Cell. 2011;23(12):4208-20.

50. Silva EN, Ribeiro RV, Ferreira-Silva SL, Vieira SA, Ponte LFA, Silveira JAG Coordinate changes in photosynthesis, sugar accumulation and antioxidative enzymes improve the performance of Jatropha curcas plants under drought stress. Biomass Bioenergy. 2012;45:270-9.

51. Ranjith SA, Meinzer FC, Perry MH, Thom M. Partitioning of carboxylase activity in nitrogen-stressed sugarcane and its relationship to bundle sheath leakiness to CO2, photosynthesis and carbon isotope discrimination. Austr J Plant Physiol. 1995;22(6):903-11.

52. Buchmann N, Brooks JR, Rapp KD, Ehleringer JR. Carbon isotope composition of C-4 grasses is influenced by light and water supply. Plant Cell Environ. 1996;19(4):392-402.

53. Saliendra NZ, Meinzer FC, Perry M, Thom M. Associations between partitioning of carboxylase activity and bundle sheath leakiness to $\mathrm{CO}_{2}$, carbon isotope discrimination, photosynthesis, and growth in sugarcane. J Exp Bot. 1996;47(300):907-14.

54. Schulze ED, Ellis R, Schulze W, Trimborn P. Diversity, metabolic types and delta C-13 carbon isotope ratios in the grass flora of Namibia in relation to growth form, precipitation and habitat conditions. Oecologia. 1996;106(3):352-69.

55. Meinzer FC, Zhu J. Nitrogen stress reduces the efficiency of the $\mathrm{C}_{4} \mathrm{CO}_{2}$ concentrating system, and therefore quantum yield, in Saccharum (sugarcane) species. J Exp Bot. 1998;49(324):1227-34

56. Williams DG, Gempko V, Fravolini A, Leavitt SW, Wall GW, Kimball BA, et al. Carbon isotope discrimination by Sorghum bicolor under $\mathrm{CO}_{2}$ enrichment and drought. New Phytol. 2001;150(2):285-93.

57. Cernusak LA, Ubierna N, Winter K, Holtum JA, Marshall JD GDF. Environmental and physiological determinants of carbon isotope discrimination in terrestrial plants. New Phytol. 2013;200:950-65.

58. Kromdijk J, Griffiths H, Schepers HE. Can the progressive increase of $C_{4}$ bundle sheath leakiness at low PFD be explained by incomplete suppression of photorespiration? Plant Cell Environ. 2010;33(11):1935-48.

59. Kromdijk J, Schepers HE, Albanito F, Fitton N, Carroll F, Jones MB, et al. Bundle sheath leakiness and light limitation during $\mathrm{C}_{4}$ leaf and canopy $\mathrm{CO}_{2}$ uptake. Plant Physiol. 2008;148(4):2144-55.

60. Ubierna N, Sun W, Kramer DM, Cousins AB. The efficiency of $C_{4}$ photosynthesis under low light conditions in Zea mays, Miscanthus $x$ giganteus and Flaveria bidentis. Plant Cell Environ. 2013;36(2):365-81.

61. Ubierna $N$, Sun $W$, Cousins AB. The efficiency of $C_{4}$ photosynthesis under low light conditions: assumptions and calculations with $\mathrm{CO}_{2}$ isotope discrimination. J Exp Bot. 2011;62(9):3119-34.

62. Xu Z, Zhou G. Responses of leaf stomatal density to water status and its relationship with photosynthesis in a grass. J Exp Bot. 2008;59(12):3317-25. 
63. Ocheltree TW, Nippert JB, Prasad PV. Changes in stomatal conductance along grass blades reflect changes in leaf structure. Plant Cell Environ. 2012;35(6):1040-9.

64. Li HL, Zhao CJ, Huang WJ, Yang GJ. Non-uniform vertical nitrogen distribution within plant canopy and its estimation by remote sensing: A review. Field Crops Res. 2013;142:75-84.

65. Valluru R, Van den Ende W. Myo-inositol and beyond - Emerging networks under stress. Plant Sci. 2011;181(4):387-400.

66. Perez-Rodriguez P, Riano-Pachon DM, Correa LGG, Rensing SA, Kersten B, Mueller-Roeber B. PInTFDB: updated content and new features of the plant transcription factor database. Nucleic Acids Res. 2010;38:D822-7.

67. Robinson MD, McCarthy DJ, Smyth GK. edgeR: a Bioconductor package for differential expression analysis of digital gene expression data. Bioinformatics. 2010;26(1):139-40.

68. Ono M, Hiyama S, Higuchi Y, Kamada H, Nitasaka E, Koyama T, et al. Morphological changes in Ipomoea nil using chimeric repressors of Arabidopsis TCP3 and TCP5. Plant Biotechnol. 2012;29(5):457-63.

69. Tao Q, Guo DS, Wei BY, Zhang F, Pang CX, Jiang H, et al. The TIE1 transcriptional repressor links TCP transcription factors with TOPLESS/ TOPLESS-RELATED corepressors and modulates leaf development in Arabidopsis. Plant Cell. 2013;25(2):421-37.

70. Ikeda M, Ohme-Takagi M. TCPs, WUSs, and WINDs: families of transcription factors that regulate shoot meristem formation, stem cell maintenance, and somatic cell differentiation. Front Plant Sci. 2014;5:427.

71. Aggarwal P, Padmanabhan B, Bhat A, Sarvepalli K, Sadhale PP, Nath U. The TCP4 transcription factor of Arabidopsis blocks cell division in yeast at G1 -> S transition. Biochem Biophys Res Commun. 2011;410(2):276-81.

72. Koyama T, Sato F, Ohme-Takagi M. A role of TCP1 in the longitudinal elongation of leaves in Arabidopsis. Biosci Biotechnol Biochem. 2010;74(10):2145-7.

73. Koyama T, Mitsuda N, Seki M, Shinozaki K, Ohme-Takagi M. TCP transcription factors regulate the activities of ASYMMETRIC LEAVES1 and miR164, as well as the auxin response, during differentiation of leaves in Arabidopsis. Plant Cell. 2010;22(11):3574-88

74. Bischoff V, Nita S, Neumetzler L, Schindelasch D, Urbain A, Eshed R, et al. TRICHOME BIREFRINGENCE and its homolog AT5G01360 encode plantspecific DUF231 proteins required for cellulose biosynthesis in Arabidopsis. Plant Physiol. 2010;153(2):590-602.

75. Gille S, de Souza A, Xiong GY, Benz M, Cheng K, Schultink A, et al. OAcetylation of Arabidopsis hemicellulose xyloglucan requires $A X Y 4$ or $A X Y 4 L$, proteins with a TBL and DUF231 domain. Plant Cell. 2011;23(11):4041-53.

76. Gille S, Pauly M. O-acetylation of plant cell wall polysaccharides. Front Plant Sci. 2012:3:12

77. Nielsen JS, Moller BL. Biosynthesis of cyanogenic glucosides in Triglochin maritima and the involvement of cytochrome P450 enzymes. Arch Biochem Biophys. 1999;368(1):121-30.

78. Nielsen JS, Moller BL. Cloning and expression of cytochrome P450 enzymes catalyzing the conversion of tyrosine to $\mathrm{p}$-hydroxyphenylacetaldoxime in the biosynthesis of cyanogenic glucosides in Triglochin maritima. Plant Physiol. 2000;122(4):1311-21.

79. Burke JJ, Chen JP, Burow G, Mechref Y, Rosenow D, Payton P, et al. Leaf dhurrin content is a quantitative measure of the level of pre- and postflowering drought tolerance in Sorghum. Crop Sci. 2013;53(3):1056-65.

80. Curto G, Dallavalle E, De Nicola GR, Lazzeri L. Evaluation of the activity of dhurrin and sorghum towards Meloidogyne incognita. Nematology. 2012:14:759-69.

81. Busk PK, Moller BL. Dhurrin synthesis in sorghum is regulated at the transcriptional level and induced by nitrogen fertilization in older plants. Plant Physiol. 2002;129(3):1222-31.

82. Link M, Rausch T, Greiner S. In Arabidopsis thaliana, the invertase inhibitors AtCNIF1 and 2 exhibit distinct target enzyme specificities and expression profiles. Febs Letters. 2004;573(1-3):105-9.

83. Tamoi M, Tabuchi T, Demuratani M, Otori $\mathrm{K}$, Tanabe N, Maruta $\mathrm{T}$, et al. Point mutation of a plastidic invertase inhibits development of the photosynthetic apparatus and enhances nitrate assimilation in sugar-treated Arabidopsis seedlings. J Biol Chem. 2010;285(20):15399-407.

84. Carland F, Fujioka S, Nelson T. The sterol methyltransferases SMT1, SMT2, and SMT3 influence Arabidopsis development through nonbrassinosteroid products. Plant Physiol. 2010;153(2):741-56.

85. Giovane A, Servillo L, Balestrieri C, Raiola A, D'Avino R, Tamburrini M, et al. Pectin methylesterase inhibitor. Biochim Biophys Acta Proteins Proteomics. 2004;1696(2):245-52
86. Davin LB, Lewis NG. Dirigent proteins and dirigent sites explain the mystery of specificity of radical precursor coupling in lignan and lignin biosynthesis. Plant Physiol. 2000;123(2):453-61.

87. Darnet S, Rahier A. Plant sterol biosynthesis: identification of two distinct families of sterol 4 alpha-methyl oxidases. Biochem J. 2004;378:889-98.

88. Bloch KE. Sterol structure and membrane-function. Crit Rev Biochem. 1983;14(1):47-92.

89. Hartmann MA. Plant sterols and the membrane environment. Trends Plant Sci. 1998;3(5):170-5.

90. Chen ZX. A superfamily of proteins with novel cysteine-rich repeats. Plant Physiol. 2001;126(2):473-6.

91. Liu ML, Li XR, Liu YB, Cao B. Regulation of flavanone 3-hydroxylase gene involved in the flavonoid biosynthesis pathway in response to UV-B radiation and drought stress in the desert plant, Reaumuria soongorica. Plant Physiol Biochem. 2013:73:161-7.

92. Winkel-Shirley B. Flavonoid biosynthesis. A colorful model for genetics, biochemistry, cell biology, and biotechnology. Plant Physiol. 2001;126(2):485-93.

93. Matkovich SJ, Zhang Y, Van Booven DJ, Dorn GW. Deep mRNA sequencing for in vivo functional analysis of cardiac transcriptional regulators application to G alpha q. Circ Res. 2010;106(9):1459-67.

94. Liu S, Lin L, Jiang P, Wang D, Xing Y. A comparison of RNA-Seq and highdensity exon array for detecting differential gene expression between closely related species. Nucleic Acids Res. 2011;39(2):578-88.

95. Mortazavi A, Williams BA, McCue K, Schaeffer L, Wold B. Mapping and quantifying mammalian transcriptomes by RNA-Seq. Nat Methods. 2008;5(7):621-8

96. Brautigam A, Weber APM. Do metabolite transport processes limit photosynthesis? Plant Physiol. 2011;155(1):43-8.

97. Gowik U, Bräutigam A, Weber KL, Weber AP, Westhoff P. Evolution of $C_{4}$ photosynthesis in the genus Flaveria: how many and which genes does it take to make $C_{4}$ ? Plant Cell. 2011:23(6):2087-105.

98. Kausch AP, Owen TP, Zachwieja SJ, Flynn AR, Sheen J. Mesophyll-specific, light and metabolic regulation of the C(4)PPCZm1 promoter in transgenic maize. Plant Mol Biol. 2001;45(1):1-15

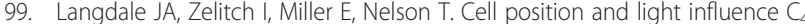
versus $C_{3}$ patterns of photosynthetic gene-expression in maize. Embo $\mathrm{J}$. 1988;7(12):3643-51.

100. Wingler A, Walker RP, Chen ZH, Leegood RC. Phosphoenolpyruvate carboxykinase is involved in the decarboxylation of aspartate in the bundle sheath of maize. Plant Physiol. 1999;120(2):539-45.

101. Sheen J. $C_{4}$ gene expression. Annu Rev Plant Physiol Plant Mol Biol. 1999:50:187-217.

102. Ueno $Y$, Imanari E, Emura J, Yoshizawa-Kumagaye $K$, Nakajima $K$, Inami $K$, et al. Immunological analysis of the phosphorylation state of maize $\mathrm{C}_{4}$-form phosphoenolpyruvate carboxylase with specific antibodies raised against a synthetic phosphorylated peptide. Plant J. 2000;21(1):17-26.

103. Ponnala L, Wang YP, Sun Q, van Wijk KJ. Correlation of mRNA and protein abundance in the developing maize leaf. Plant J. 2014:78(3):424-40.

104. Sheen JY, Bogorad L. Differential expression of $C_{4}$ pathway genes in mesophyll and bundle sheath-cells of greening maize leaves. J Biol Chemis. 1987;262(24):11726-30.

105. Langdale JA, Rothermel BA, Nelson T. Cellular-pattern of photosynthetic gene-expression in developing maize leaves. Genes Dev. 1988;2(1):106-15.

106. Rius SP, Casati P, Iglesias AA, Gomez-Casati DF. Characterization of an Arabidopsis thaliana mutant lacking a cytosolic non-phosphorylating glyceraldehyde-3-phosphate dehydrogenase. Plant Mol Biol. 2006;61(6):945-57

107. Lunn JE, Delorge I, Figueroa CM, Van Dijck P, Stitt M. Trehalose metabolism in plants. Plant J. 2014;79(4):544-67.

108. Yadav UP, Ivakov A, Feil R, Duan GY, Walther D, Giavalisco P, et al. The sucrosetrehalose 6-phosphate (Tre6P) nexus: specificity and mechanisms of sucrose signalling by Tre6P. J Exp Bot. 2014:65(4):1051-68.

109. Delorge I, Figueroa CM, Feil R, Lunn JE, Van Dijck P. Trehalose-6-phosphate synthase 1 is not the only active TPS in Arabidopsis thaliana. Biochem J. 2015;466:283-90

110. Loewus FA, Murthy PPN. Myo-inositol metabolism in plants. Plant Sci. 2000;150(1):1-19.

111. Gillaspy GE. The cellular language of myo-inositol signaling. New Phytologist. 2011;192(4):823-39. 
112. Stitt M, Gibon Y. Why measure enzyme activities in the era of systems biology? Trends Plant Sci. 2014;19(4):256-65.

113. Cosgrove D. Growth of the plant cell wall. Nat Rev Mol Cell Biol. 2005:6(11):850-61.

114. Sorek N, Sorek H, Kijac A, Szemenyei HJ, Bauer S, Hematy K, et al. The Arabidopsis COBRA protein facilitates cellulose crystallization at the plasma membrane. J Biol Chem. 2014;289(50):34911-20.

115. Ranathunge K, Schreiber L, Franke R. Suberin research in the genomics eraNew interest for an old polymer. Plant Sci. 2011;180(3):399-413.

116. Kosma DK, Murmu J, Razeq FM, Santos P, Bourgault R, Molina I, et al. AtMYB41 activates ectopic suberin synthesis and assembly in multiple plant species and cell types. Plant J. 2014;80(2):216-29.

117. Mertz RA, Brutnell TP. Bundle sheath suberization in grass leaves: multiple barriers to characterization. J Exp Bot. 2014;65(13):3371-80.

118. Hattersley PW. DeltaC13 values of $\mathrm{C}_{4}$ types in grasses. Austr J Plant Physiol. 1982;9(2):139-54.

119. Hatch MD, Agostino A, Jenkins CLD. Measurement of the leakage of $\mathrm{CO}_{2}$ from bundle-sheath cells of leaves during $\mathrm{C}_{4}$ photosynthesis. Plant Physiol. 1995;108(1):173-81.

120. Soler M, Serra O, Molinas M, Huguet G, Fluch S, Figueras M. A genomic approach to suberin biosynthesis and cork differentiation. Plant Physiol. 2007;144(1):419-31.

121. Dubos C, Stracke R, Grotewold E, Weisshaar B, Martin C, Lepiniec L. MYB transcription factors in Arabidopsis. Trends Plant Sci. 2010;15(10):573-81.

122. Zhong $\mathrm{RQ}$, Ye $\mathrm{ZH}$. Complexity of the transcriptional network controlling secondary wall biosynthesis. Plant Sci. 2014;229:193-207.

123. Chai MF, Bellizzi M, Wan CX, Cui ZF, Li YB, Wang GL. The NAC transcription factor OsSWN1 regulates secondary cell wall development in Oryza sativa. J Plant Biol. 2015;58(1):44-51.

124. Ludwig Y, Berendzen KW, Xu CZ, Piepho HP, Hochholdinger F. Diversity of stability, localization, interaction and control of downstream gene activity in the maize Aux/IAA protein family. Plos One. 2014;9(9), e107346.

125. Mockaitis K, Estelle M. Auxin receptors and plant development: A new signaling paradigm. In: Annual Review of Cell and Developmental Biology, vol. 24. Palo Alto: Annual Reviews; 2008. p. 55-80.

126. Balcerowicz M, Ranjan A, Rupprecht L, Fiene G, Hoecker U. Auxin represses stomatal development in dark-grown seedlings via Aux/IAA proteins. Development. 2014;141(16):3165-76.

127. Wang YJ, Deng DX, Bian YL, LV YP, Xie Q. Genome-wide analysis of primary auxin-responsive Aux/IAA gene family in maize (Zea mays. L.). Mol Biol Rep. 2010;37(8):3991-4001.

128. Huang CJ, Hu GJ, Li FF, Li YQ, Wu JX, Zhou XP. NbPHAN, a MYB transcriptional factor, regulates leaf development and affects drought tolerance in Nicotiana benthamiana. Physiol Plant. 2013;149(3):297-309.

129. Naz AA, Raman S, Martinez CC, Sinha NR, Schmitz G, Theres K. Trifoliate encodes an MYB transcription factor that modulates leaf and shoot architecture in tomato. Proc Natl Acad Sci U S A. 2013;110(6):2401-6.

130. Juarez MT, Twigg RW, Timmermans MCP. Specification of adaxial cell fate during maize leaf development. Development. 2004;131(18):4533-44.

131. Liu T, Ohashi-Ito K, Bergmann DC. Orthologs of Arabidopsis thaliana stomatal bHLH genes and regulation of stomatal development in grasses. Development. 2009;136(13):2265-76.

132. Li ZY, Li B, Dong AW. The Arabidopsis transcription factor AtTCP15 regulates endoreduplication by modulating expression of key cell-cycle genes. Mol Plant. 2012:5(1):270-80

133. Kieffer M, Master $V$, Waites R, Davies B. TCP14 and TCP15 affect internode length and leaf shape in Arabidopsis. Plant J. 2011;68(1):147-58.

134. Steiner E, Efroni I, Gopalraj M, Saathoff K, Tseng TS, Kieffer M, et al. The Arabidopsis o-linked $n$-acetylglucosamine transferase SPINDLY interacts with class I TCPs to Facilitate cytokinin responses in leaves and flowers. Plant Cell. 2012;24(1):96-108.

135. Uberti-Manassero NG, Lucero LE, Viola IL, Vegetti AC, Gonzalez DH. The class I protein AtTCP15 modulates plant development through a pathway that overlaps with the one affected by CIN-like TCP proteins. J Exp Bot. 2012;63(2):809-23.

136. Balazadeh S, Riano-Pachon DM, Mueller-Roeber B. Transcription factors regulating leaf senescence in Arabidopsis thaliana. Plant Biol. 2008;10: 63-75.

137. Riechmann JL, Heard J, Martin G, Reuber L, Jiang CZ, Keddie J, et al. Arabidopsis transcription factors: Genome-wide comparative analysis among eukaryotes. Science. 2000;290(5499):2105-10.
138. Xu XP, Chen CH, Fan BF, Chen ZX. Physical and functional interactions between pathogen-induced Arabidopsis WRKY18, WRKY40, and WRKY60 transcription factors. Plant Cell. 2006;18(5):1310-26.

139. Fang YJ, You J, Xie KB, Xie WB, Xiong LZ. Systematic sequence analysis and identification of tissue-specific or stress-responsive genes of NAC transcription factor family in rice. Mol Genet Genomics. 2008; 280(6):547-63.

140. Okamoto M, Vidmar JJ, Glass ADM. Regulation of NRT1 and NRT2 gene families of Arabidopsis thaliana: Responses to nitrate provision. Plant Cell Physiol. 2003;44(3):304-17.

141. Robinson SA, Slade AP, Fox GG, Phillips R, Ratcliffe RG, Stewart GR. The role of glutamate-dehydrogenase in plant nitrogen-metabolism. Plant Physiol. 1991:95(2):509-16.

142. Tamura W, Hidaka Y, Tabuchi M, Kojima S, Hayakawa T, Sato T, et al. Reverse genetics approach to characterize a function of NADH-glutamate synthase1 in rice plants. Amino Acids. 2010;39(4):1003-12.

143. Prinsi B, Espen L. Mineral nitrogen sources differently affect root glutamine synthetase isoforms and amino acid balance among organs in maize. BMC Plant Biol. 2015:15:13.

144. Sechley KA, Yamaya T, Oaks A. Compartmentation of nitrogen assimilation in higher-plants. Int Rev Cytol. 1992;134:85-163.

145. Feild TS, Lee DW, Holbrook NM. Why leaves turn red in autumn. The role of anthocyanins in senescing leaves of red-osier dogwood. Plant Physiol. 2001;127(2):566-74.

146. Gepstein S. Leaf senescence - not just a 'wear and tear' phenomenon. Genome Biol. 2004;5:212

147. Guo YF, Gan SS. Leaf senescence: Signals, execution, and regulation. Curr Top Dev Biol. 2005:71:83-112.

148. Zhou QY, Tian AG, Zou HF, Xie ZM, Lei G, Huang J, et al. Soybean WRKYtype transcription factor genes, GmWRKY13, GmWRKY21, and GmWRKY54, confer differential tolerance to abiotic stresses in transgenic Arabidopsis plants. Plant Biotech J. 2008;6(5):486-503.

149. Vangysel A, Vanmontagu M, Inze D. A negatively light-regulated gene from Arabidopsis thaliana encodes a protein showing high similarity to blue copper-binding proteins. Gene. 1993;136(1-2):79-85.

150. Stone SL, Hauksdottir H, Troy A, Herschleb J, Kraft E, Callis J. Functional analysis of the RING-type ubiquitin ligase family of Arabidopsis. Plant Physiol. 2005;137(1):13-30.

151. Miao $Y$, Zentgraf U. A HECT E3 ubiquitin ligase negatively regulates Arabidopsis leaf senescence through degradation of the transcription factor WRKY53. Plant J. 2010;63(2):179-88.

152. Berghold J, Breuker K, Oberhuber M, Hortensteiner S, Krautler B. Chlorophyll breakdown in spinach: on the structure of five nonfluorescent chlorophyll catabolites. Photosynth Res. 2002;74(2):109-19.

153. Hortensteiner S. Stay-green regulates chlorophyll and chlorophyll-binding protein degradation during senescence. Trends Plant Sci. 2009;14(3):155-62.

154. Park SY, Yu JW, Park JS, Li J, Yoo SC, Lee NY, et al. The senescence-induced staygreen protein regulates chlorophyll degradation. Plant Cell. 2007:19(5):1649-64.

155. Neill SJ, Burnett EC, Desikan R, Hancock JT. Cloning of a wilt-responsive cDNA from an Arabidopsis thaliana suspension culture cDNA library that encodes a putative 9-cis-epoxy-carotenoid dioxygenase. J Exp Bot. 1998; 49(328):1893-4.

156. Barry C, Fox E, Yen H, Lee S, Ying T, Grierson D, et al. Analysis of the ethylene response in the epinastic mutant of tomato. Plant Physiol. 2001;127(1):58-66

157. Kim J, Chang C, Tucker ML. To grow old: regulatory role of ethylene and jasmonic acid in senescence. Front Plant Sci. 2015;6:20.

158. Picton S, Barton SL, Bouzayen M, Hamilton AJ, Grierson D. Altered fruit ripening and leaf senescence in tomatoes expressing an antisense ethyleneforming enzyme transgene. Plant J. 1993;3(3):469-81.

159. Grbic V, Bleecker AB. Ethylene regulates the timing of leaf senescence in Arabidopsis. Plant J. 1995;8(4):595-602.

160. John I, Drake R, Farrell A, Cooper W, Lee P, Horton P, et al. Delayed leaf senescence in ethylene-deficient ACC-oxidase antisense tomato plants Molecular and physiological analysis. Plant J. 1995;7(3):483-90.

161. Yang TF, Gonzalez-Carranza ZH, Maunders MJ, Roberts JA. Ethylene and the regulation of senescence processes in transgenic Nicotiana sylvestris plants. Ann Bot. 2008;101(2):301-10.

162. Hochheiser $H$, Shneiderman B. Dynamic query tools for time series data sets, Timebox widgets for interactive exploration. Inf Vis. 2004;3(1):1-18. 
163. Sade N, Shatil-Cohen A, Attia Z, Maurel C, Boursiac Y, Kelly G, et al. The role of plasma membrane aquaporins in regulating the bundle sheath-mesophyll continuum and leaf hydraulics. Plant Physiol. 2014;166(3):1609-20.

164. Franken P, Schrell S, Peterson PA, Saedler H, Wienand U. Molecular analysis of protein domain function encoded by the myb-homologous maize geneC1, gene-ZM-1 and gene-ZM-38. Plant J. 1994;6(1):21-30.

165. Glover BJ, Perez-Rodriguez M, Martin C. Development of several epidermal cell types can be specified by the same MYB-related plant transcription factor. Development. 1998;125(17):3497-508.

166. Lee MM, Schiefelbein J. WEREWOLF, a MYB-related protein in arabidopsis, is a position-dependent regulator of epidermal cell patterning. Cell. 1999;99(5):473-83.

167. Vaucheret H. Plant ARGONAUTES. Trends Plant Sci. 2008;13(7):350-8.

168. Ferreira TH, Gentile A, Vilela RD, Costa GGL, Dias LI, Endres L, et al. microRNAs associated with drought response in the bioenergy crop sugarcane (Saccharum spp.). Plos One. 2012;7(10):14.

169. Gentile A, Ferreira TH, Mattos RS, Dias LI, Hoshino AA, Carneiro MS, et al. Effects of drought on the microtranscriptome of field-grown sugarcane plants. Planta. 2013;237(3):783-98

170. Bottino MC, Rosario S, Grativol C, Thiebaut F, Rojas CA, Farrineli L, et al. High-throughput sequencing of small rna transcriptome reveals salt stress regulated microRNAs in Sugarcane. Plos One. 2013;8(3):12.

171. Nonomura Kl, Morohoshi A, Nakano M, Eiguchi M, Miyao A, Hirochika H, et al. A germ cell-specific gene of the ARGONAUTE family is essential for the progression of premeiotic mitosis and meiosis during sporogenesis in rice. Plant Cell. 2007;19(8):2583-94.

172. Olmedo-Monfil V, Duran-Figueroa N, Arteaga-Vazquez M, Demesa-Arevalo E, Autran D, Grimanelli D, et al. Control of female gamete formation by a small RNA pathway in Arabidopsis. Nature. 2010;464:628-32.

173. Bohmert K, Camus I, Bellini C, Bouchez D, Caboche M, Benning C. AGO1 defines a novel locus of Arabidopsis controlling leaf development. EMBO J. 1998;17(1):170-80.

174. Lynn K, Fernandez A, Aida M, Sedbrook J, Tasaka M, Masson P, et al. The PINHEAD/ZWILLE gene acts pleiotropically in Arabidopsis development and has overlapping functions with the ARGONAUTE1 gene. Development. 1999:126(3):469-81.

175. Moussian B, Schoof $H$, Haecker A, Jurgens G, Laux T. Role of the ZWILLE gene in the regulation of central shoot meristem cell fate during Arabidopsis embryogenesis. EMBO J. 1998;17(6):1799-809.

176. Yang $K Z$, Jiang $M$, Le J. A new loss-of-function allele $28 y$ reveals a role of ARGONAUTE1 in limiting asymmetric division of stomatal lineage ground cell. J Integr Plant Biol. 2014;56(6):539-49.

177. Oliver C, Santos JL, Pradillo M. On the role of some ARGONAUTE proteins in meiosis and DNA repair in Arabidopsis thaliana. Front Plant Sci. 2014:5:177.

178. Nagasaki H, Itoh Jl, Hayashi K, Hibara Kl, Satoh-Nagasawa N, Nosaka M, et al. The small interfering RNA production pathway is required for shoot meristern initiation in rice. Proc Natl Acad Sci U S A. 2007;104(37):14867-71.

179. Kalve S, De Vos D, Beemster GTS. Leaf development: a cellular perspective. Front Plant Sci. 2014:5:362

180. Jia XL, Li MY, Jiang Q, Xu ZS, Wang F, Xiong AS. High-throughput sequencing of small RNAs and anatomical characteristics associated with leaf development in celery. Sci Rep. 2015; 5: doi:10.1038/srep11093.

181. Lakhotia N, Joshi G, Bhardwaj AR, Katiyar-Agarwal S, Agarwal M, Jagannath $A$, et al. Identification and characterization of miRNAome in root, stem, leaf and tuber developmental stages of potato (Solanum tuberosum L.) by highthroughput sequencing. BMC Plant Biol. 2014;14.

182. van Dillewijn C. Botany of Sugarcane. Waltahm, Massachusetts: Chronica Botanica; 1952.

183. Gibon Y, Blaesing OE, Hannemann J, Carillo P, Hohne M, Hendriks JHM, et al. A robot-based platform to measure multiple enzyme activities in Arabidopsis using a set of cycling assays: Comparison of changes of enzyme activities and transcript levels during diurnal cycles and in prolonged darkness. Plant Cell. 2004;16(12):3304-25.

184. Ashton ARB, J.N. Furbank, A.T. Jenkins, C.L.D. Hatch, M.D. Enzymes of $C_{4}$ photosynthesis. In: Methods in Plant Biochemistry. Edited by Lea P, vol. 3. London, UK: Academic Press; 1990: 39-71.

185. Lilley RM, Walker DA. Improved spectrophotometric assay for ribulose-bisphosphate carboxylase. Biochim Biophys Acta. 1974;358(1):226-9.

186. Carmo-Silva AE, Salvucci ME. The regulatory properties of Rubisco activase differ among species and affect photosynthetic induction during light transitions. Plant Physiol. 2013;161(4):1645-55.
187. Berkelman T, Stenstedt T: 2-D eletrophoresis-using immobilized pH gradients. Principles and Methods.: Amersham Biosciences; 1998.

188. Farquhar GD. On the nature of carbon isotope discrimination in $C_{4}$ species. Austr J Plant Physiol. 1983;10(2):205-26.

189. Cross JM, von Korff M, Altmann T, Bartzetko L, Sulpice R, Gibon Y, et al. Variation of enzyme activities and metabolite levels in 24 Arabidopsis accessions growing in carbon-limited conditions. Plant Physiol. 2006;142(4):1574-88.

190. Ruijter JM, Ramakers C, Hoogaars WMH, Karlen Y, Bakker O, van den Hoff $M J B$, et al. Amplification efficiency: linking baseline and bias in the analysis of quantitative PCR data. Nucleic Acids Res. 2009;37(6), e45.

191. Bolger AM, Lohse M, Usadel B. Trimmomatic: a flexible trimmer for Illumina sequence data. Bioinformatics. 2014;30(15):2114-20.

192. Grabherr MG, Haas BJ, Yassour M, Levin JZ, Thompson DA, Amit I, et al. Full-length transcriptome assembly from RNA-Seq data without a reference genome. Nat Biotech. 2011;29:644-52.

193. Haas BJ, Papanicolaou A, Yassour M, Grabherr M, Blood PD, Bowden J, et al. De novo transcript sequence reconstruction from RNA-seq using the Trinity platform for reference generation and analysis. Nat Protoc. 2013;8(8):1494-512.

194. Smith-Unna D, Boursnell C, Kelly S, Hibberd J. Transrate v1.0.0alpha. 2014. 10.5281/zenodo.12286

195. Paterson AH, Bowers JE, Bruggmann R, Dubchak I, Grimwood J, Gundlach H, et al. The Sorghum bicolor genome and the diversification of grasses. Nature. 2009;457:551-6.

196. Parra G, Bradnam K, Korf I. CEGMA: a pipeline to accurately annotate core genes in eukaryotic genornes. Bioinformatics. 2007;23(9):1061-7.

197. Petersen TN, Brunak S, von Heijne G, Nielsen H. SignalP 4.0: discriminating signal peptides from transmembrane regions. Nat Methods. 2011;8(10):785-6.

198. Krogh A, Larsson B, von Heijne G, Sonnhammer ELL. Predicting transmembrane protein topology with a hidden Markov model: Application to complete genomes. J Mol Biol. 2001;305(3):567-80.

199. Lagesen K, Hallin P, Rodland EA, Staerfeldt HH, Rognes T, Ussery DW. RNAmmer: consistent and rapid annotation of ribosomal RNA genes. Nucleic Acids Res. 2007;35(9):3100-8.

200. Moriya Y, Itoh M, Okuda S, Yoshizawa AC, Kanehisa M. KAAS: an automatic genome annotation and pathway reconstruction server. Nucleic Acids Res. 2007;35:W182-5.

201. Goodstein DM, Shu SQ, Howson R, Neupane R, Hayes RD, Fazo J, et al. Phytozome: a comparative platform for green plant genomics. Nucleic Acids Res. 2012;40(D1):D1178-86

202. Roberts A, Pachter L. Streaming fragment assignment for real-time analysis of sequencing experiments. Nat Methods. 2013;10:71-3.

203. Anders S, McCarthy DJ, Chen YS, Okoniewski M, Smyth GK, Huber W, et al. Count-based differential expression analysis of RNA sequencing data using $\mathrm{R}$ and Bioconductor. Nature Protoc. 2013;8(9):1765-86.

204. Robinson MD, Oshlack A. A scaling normalization method for differential expression analysis of RNA-seq data. Genome Biol. 2010; 11: doi:10.1186/gb-2010 $11-3-r 25$

\section{Submit your next manuscript to BioMed Central and we will help you at every step:}

- We accept pre-submission inquiries

- Our selector tool helps you to find the most relevant journal

- We provide round the clock customer support

- Convenient online submission

- Thorough peer review

- Inclusion in PubMed and all major indexing services

- Maximum visibility for your research

Submit your manuscript at www.biomedcentral.com/submit 